\title{
6 \\ Expanding Horizons in the Protohistoric Iron Age
}

\begin{abstract}
Then the gleaming-eyed goddess Athena said to him: "I will tell you these things truly: I am Mentes, son of wise Anchialos, and I rule over the oarloving Taphians. I just now came down with ship and crew, sailing on the wine-dark sea to strange-talking men, to Temesa for copper. And I bring shining iron. My ship is put up in a field away from the city, in the harbor Rheithron, under woody Neion."

- HOMER, ODYSSEY 1.179-85
\end{abstract}

In Homer, space and time come together to create imaginary places, many of which are nevertheless rooted in real locations, experiences, and cultural memory. By referring to far-flung peoples and locales, and by stitching them together in the course of a narrative, Homer illustrates a highly connected Mediterranean world-or at least one that is acutely aware of its own diversity. In the passage above, Athena, speaking to Telemachos on Ithaca, poses as Mentes, who hails from the nearby island of Taphos. She also refers to Temesa, which scholars usually locate in southwestern Italy, as a destination both familiar and foreign, and of interest for the metals trade (Papadopoulos 2001, 447). ${ }^{1}$ We are presented with information about the local topography, which "Mentes" knows. We are made aware of commodities, of strange languages, of short anchorages in unfamiliar places. Homer (especially in the Odyssey) is full of passages like this, which collapse geographical scales, multimaterial transactions, and intercultural relations into a single narrative moment that is meant to awe the listener with the vastness of the world and the capacity of characters to act within it. While this scene is part of an epic narrative, it has roots in a complex reality of increasingly contracted

1. An alternative location is sometimes given as Tamassos in Cyprus (Strabo, Geography 6.1.5). Either way, notions of significant distance obtain, though the westward orientation of much of the Odyssey (and indeed Ithaca itself) makes an Italian location more likely. On the geographic imagination in the Odyssey, see also Purves 2010, 16. 
geographical and cultural distances, along with dramatic social intensification across the Mediterranean.

Snodgrass ([1971] 2000, 416) pointed out long ago that "the changes which came over the Aegean in the eighth century are so profuse that it is hard to enumerate them in any logical order." This is reinforced by the relatively tight span of time in which many of the major developments seem to have happened. Beginning in the eighth century-in ceramic terms, in the Middle Geometric II period (see table 1) - the pace of social change in the Aegean rose dramatically, escalating especially around $750 \mathrm{BCE}$ in the transition to the Late Geometric (LG) period. Some of the most profound changes were technological, which can be seen in the form of a media revolution of images and text that spread rapidly through the Mediterranean. With the presence of contemporary texts in Greece, we reenter a period of protohistory-that is, one containing an indigenous textual and literary record, but without the specific goal of constructing a narrative of past events for informational purposes. ${ }^{2}$

The rapidity of development has led to characterizations of an eighth-century "renaissance" or "revolution" (Hägg 1983; Snodgrass [1971] 2000, 1980; Coldstream [1977] 2003; Morris 2009). Neither term, however, actually tells us much about the developments that took place among the communities of early Greece or about how those developments relate to their wider Mediterranean context. These designations also miss the crucial point that the biggest sociopolitical changes do not seem to have come until the seventh century, when we see a transition from early Greek villages representing a variety of more and less complex communities to widespread Archaic and Classical city-states (poleis).

Teleological views of the state, the polis, and urbanism have so dominated our narratives of social complexity that considerable effort is required to look at state formation as an iterative social process. When we consider the time periods under study in this book, what happened during the Geometric period in Greece had perhaps the most lasting effect of any of these eras but it is nevertheless rarely discussed in comparative terms. Moreover, rather than seeing the singular emergence of civilization or a state as an identifiable moment or process, we should broaden our perspective to allow for multiple emergences of complex social forms. This is borne out in the variety of modes of social organization seen in Archaic and Classical poleis, which we cannot really justify identifying until at least ca. 650 BCE (Hansen and Nielsen 2004). Other forms of social organization, such as ethne, were present alongside poleis, although they have received far less scholarly attention (but see, e.g., McInerney 1999; Morgan 2001, 2003, 2006; Papadopoulos 2016a).

This chapter begins by examining settlement shifts and regional networks in central Greece, which had extensive implications for territory, mobility, and social

2. This terminological distinction between "prehistory" and "protohistory" broadly follows the model of Knapp (2008). See further in the conclusions of this book, pp. 252-56. 
reorganization. Next, I turn to more revolutionary subjects: the invention of the Greek alphabet and a resurgence of figural art. I argue that these shifts in media-or modes of signification and of encountering the world-served to condense networks conceptually, even as they expanded geographically. I argue also that these developments can be viewed in terms of technology transfer, as can the modes of craft production analyzed in previous chapters. Turning to the wider Mediterranean context, we see that this is the first period in which Greek permanent settlements emerge as "frogs around a pond" (Plato, Phaedo 109b). The various regions of central Greece played a crucial role in this emergence. Central Euboea was especially outward looking, continuing in the outsized role it played through the Postpalatial Bronze Age and the Early Iron Age. Nevertheless, the relative preeminence of the Euboeans soon waned, in many ways obviated by the very networks they themselves had managed to create. With the emergence of identifiably "Greek" notions of identity, the centrality of the Euboean Gulf in Mediterranean networks was diminished not long after reaching its apex in the eighth century. ${ }^{3}$ Finally, I look ahead to the seventh- and sixth-century period of state/polis formation, bookending the examination of Mycenaean state formation at the beginning of chapter 3 .

\section{CROWDING THE LANDSCAPE: SETTLEMENT INTENSIFICATION AND REGIONAL DYNAMICS}

Three crucial developments took place in the central Greek landscape during the eighth century BCE. First, even though it continued to exhibit marked regional variability, the settlement pattern changed significantly. Second, settlement shifts in certain areas, specifically in central Euboea, shed light on wider Mediterranean dynamics (founding settlements overseas) as well as local events (a semilegendary Lelantine war). Third, the sacred landscape was reconstituted, affecting local, regional, and eventually panhellenic ritual practices and notions of identity (de Polignac 1995).

Several interrelated trends in the settlement pattern set the eighth century apart from the preceding Prehistoric Iron Age. First, there is a sharp increase in the number of sites starting in MG II, which is followed by a dramatic surge in

3. See Malkin (2011) for a discussion of the role of networks and colonization in identity formation. As an exercise, any description of "Greek" identity will be somewhat fraught. Identity must be understood as a plural, mutable, and multiscalar concept (see also the discussion of nested scales of political and spatial units in chapter 1, figure 1). In this way, people can have local identities based on common daily practices or encounters with the landscape, or regional identities based on shared language, practices, etc. In referring to "Greek" identity, I mean that communities spread over very long distances shared aspects of culture, including language, religious practices, and mythohistorical traditions. This is not to obscure major differences between different groups but rather to say that notions of a "Greek" identity formed in the early first millennium BCE as interactions across the Mediterranean created a greater awareness of cultural differences. Around the same time, similarities were reinforced through the participation in common practices, such as regional and Panhellenic political and religious festivals, which were self-ascribed as exclusively Greek. See also Hall 1997, 2002; Jones 1997. 
the Late Geometric period (map 24). The total number of sites in the study area rises from 152 in the Prehistoric Iron Age to 203 in the eighth century, representing a 33 percent increase. In parallel, the number of communities changes from 110 to 136 , which is a 23 percent increase. The overall number of sites in the Greek mainland and Crete increases from 600 in the Protogeometric period to 948 in the Geometric period (a 58 percent increase), signaling a significant difference between central Greece and elsewhere in the earlier Iron Age and attributable, at least in part, to much lower site numbers in the Peloponnese during Protogeometric times (see table 5; see also Murray 2017, 141, table 3.12). ${ }^{4}$

While the pattern for central Greece (and the wider Greek world) is certainly one of growth, there is again considerable regional variation. Indeed, there is more regional discrepancy in this period than in any other (see figure 2). While Euboea and Phokis experienced marginal growth, East Lokris and Malis experienced a decline in the number of sites, and Thessaly had a significant drop-from 35 to 26. Meanwhile, Attica and Boeotia saw a veritable explosion of settlement. In Boeotia, the number of sites nearly doubled-from 24 to 47. In Attica, a similar trend can be observed, as site numbers increased from 21 to 55 . Such a rapid expansion of settlement warrants explanation. Bintliff (1999) has discussed this trend in terms of competition for agricultural land and steady expansion, beginning in the Geometric period and culminating in the Classical period. He also notes the similarity between Attica and Boeotia and the ways in which Renfrew's (1975, 12-21) Early State Module can explain the rise of centers at Athens and Thebes: the growth of powerful centers within a region and the interaction between centers and the surrounding communities eventually led to increased integration (Bintliff 1999, 24-25). This also invokes peer-polity interaction, where connections between places intensify through a variety of forms of competition-as Snodgrass (1986) has shown in the case of early Greece.

In the nearest-neighbor model presented here, the expanding number of sites would have involved increased interaction between them, simply on account of their closer proximity (map 25). There seems to have been significant population growth as well; this observation is based on the numbers of sites and is supported by models of demographic growth leading up to the Classical period, from which we can ascertain better information (Murray 2017, 234).

On a regional level, the more frequent interfaces between more communities may have strengthened regional notions of common identity, on the one hand, and, on the other, made interaction over greater distances less necessary in order to make suitable marriages and exchange necessary goods. These factors would also have engendered the creation of hubs as central places where representatives from

4. A further note relevant to site numbers is that the Protogeometric period lasts only about 150 years, while the Geometric is at least 200 years-probably closer to 250 if it extends into the seventh century BCE. This difference in timescale may skew the data one way, which may be skewed the other way by considering - as here-a Prehistoric Iron Age of 250 years and a Protohistoric Iron Age of 150 to 200 years. More important, however, is the issue of regional and diachronic variation. 


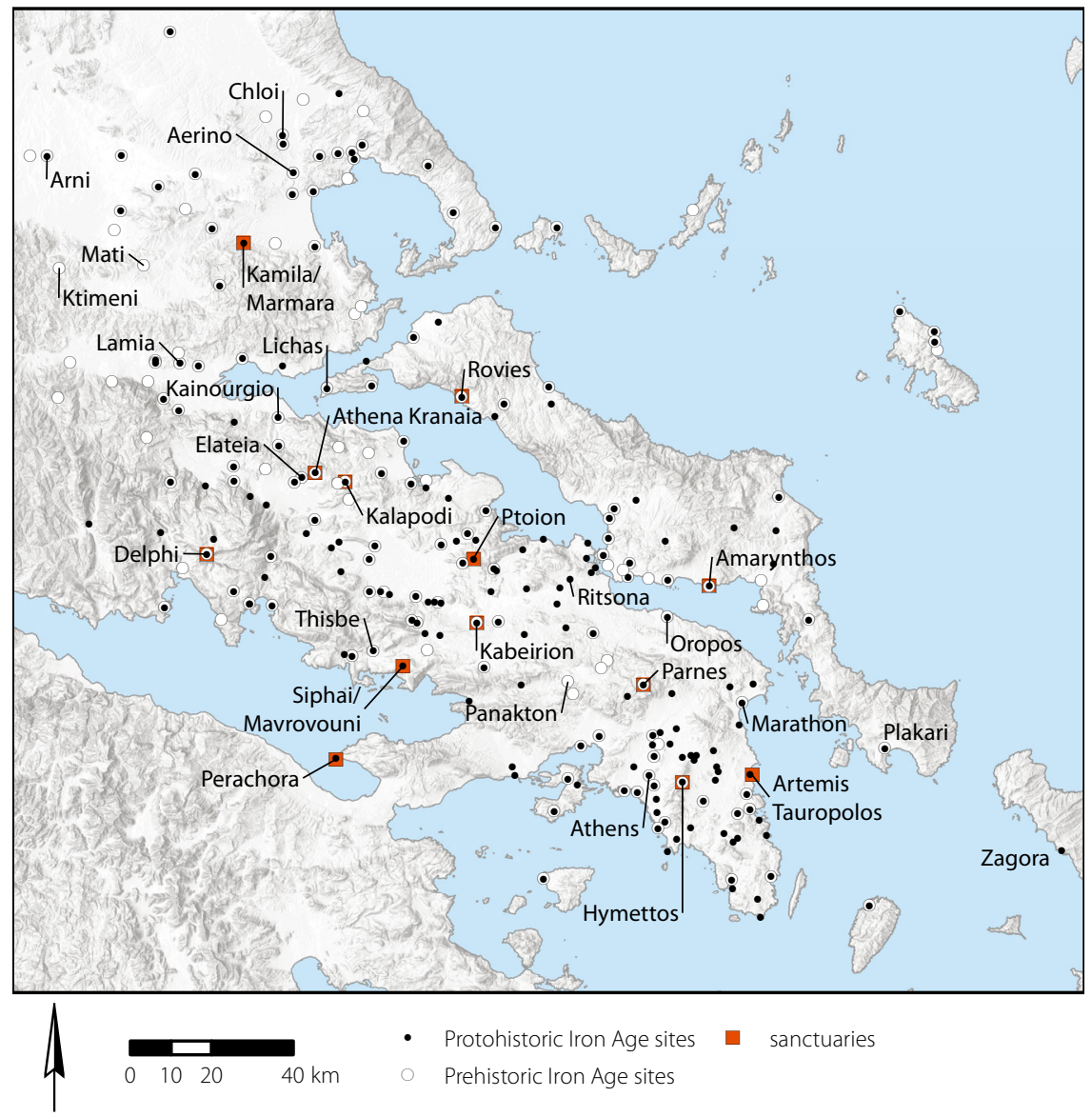

MAP 24. Protohistoric Iron Age site locations compared to the Prehistoric Iron Age, also showing select extra-urban sanctuary sites.

different communities could bring together goods and ideas. While centralization around major settlements, such as Thebes and Athens, was no doubt happening, this was very different from the type of political and economic centralization that occurred in palatial areas during Mycenaean times. It seems rather that different political formations were at play here, in a manner that is perhaps in line with Morris's (1987) "middling" effect, which caused a fissioning of the small-scale but still complex communities of the Postpalatial Bronze Age and Prehistoric Iron Age. 5 Small $(2019,126-29)$ also invokes fissioning in arguing that social differences on an individual scale (especially wealth differences) that are not recognized institutionally would have created problems in Early Iron Age societies, and that, by the eighth century, these differences would have been driving certain communities

5. For a useful critique of Morris's “middling ideology," see Duplouy 2006. 


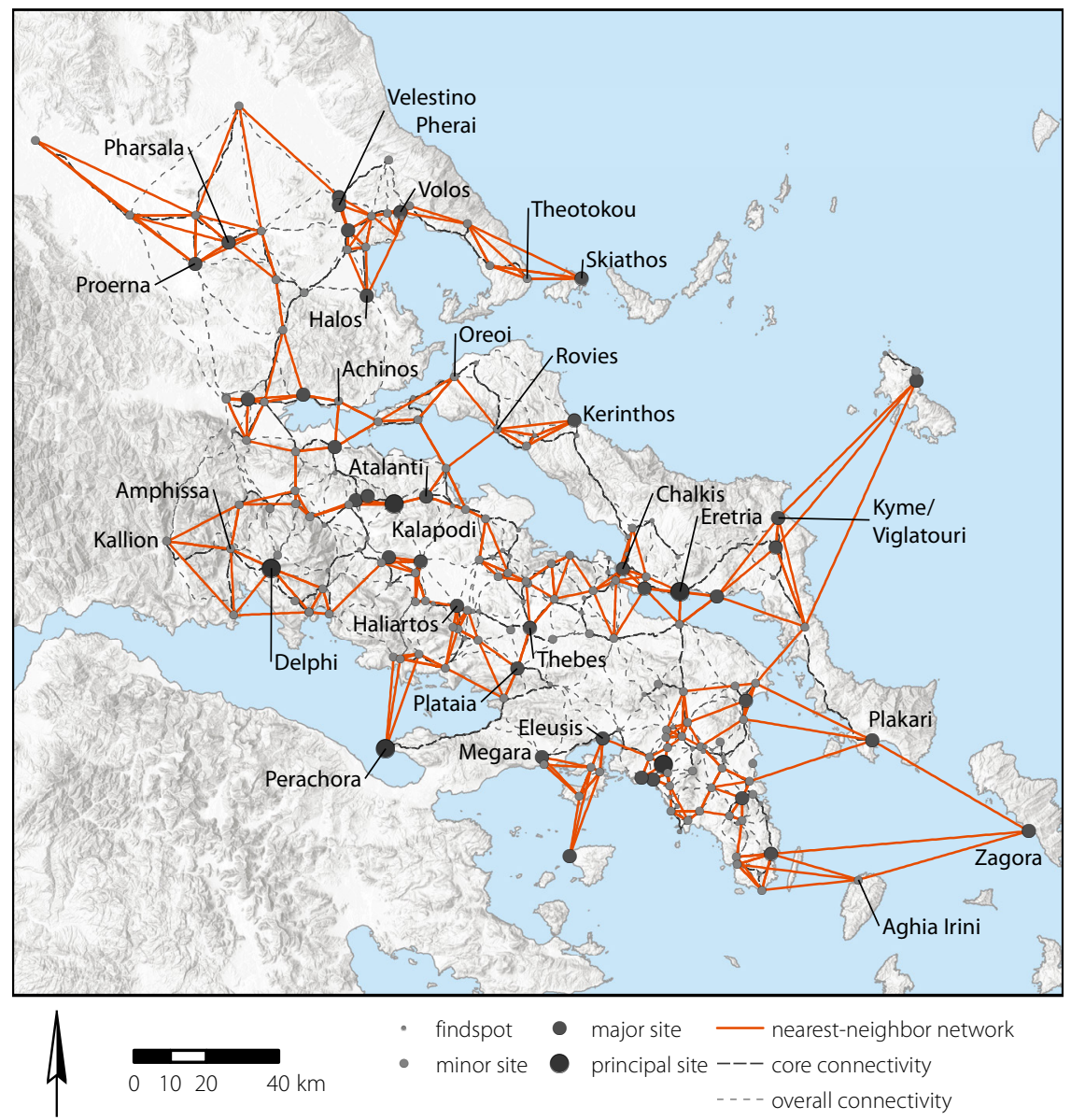

MAP 25. Protohistoric Iron Age sites, joined by a connectivity model, with a nearest-neighbor network of communities (see also map 24 and appendix for additional place names).

to break up. Such fission-fusion patterns of oscillation are documented also in the Pueblo societies of the pre-Hispanic American Southwest, in Mississippian chiefdoms, and in the formative period of the Titicaca basin, especially in response to scalar stress (McGuire and Saitta 1996; Blitz 1999; Bandy 2004). In the early Greek case, stressors such as population growth, a tightening of the settlement pattern, and growing inequality seem to have obtained in various parts of the landscape.

The close proximity of sites also would have influenced the ways in which territory was conceived. Taking notional site catchments of 2.5 kilometers around individual communities as a starting point (see chapter 2, p. 60), we can see that in the Prehistoric Iron Age there would have been little overlap of community territories in Boeotia and Attica, which suggests less competition for resources or stimulus 


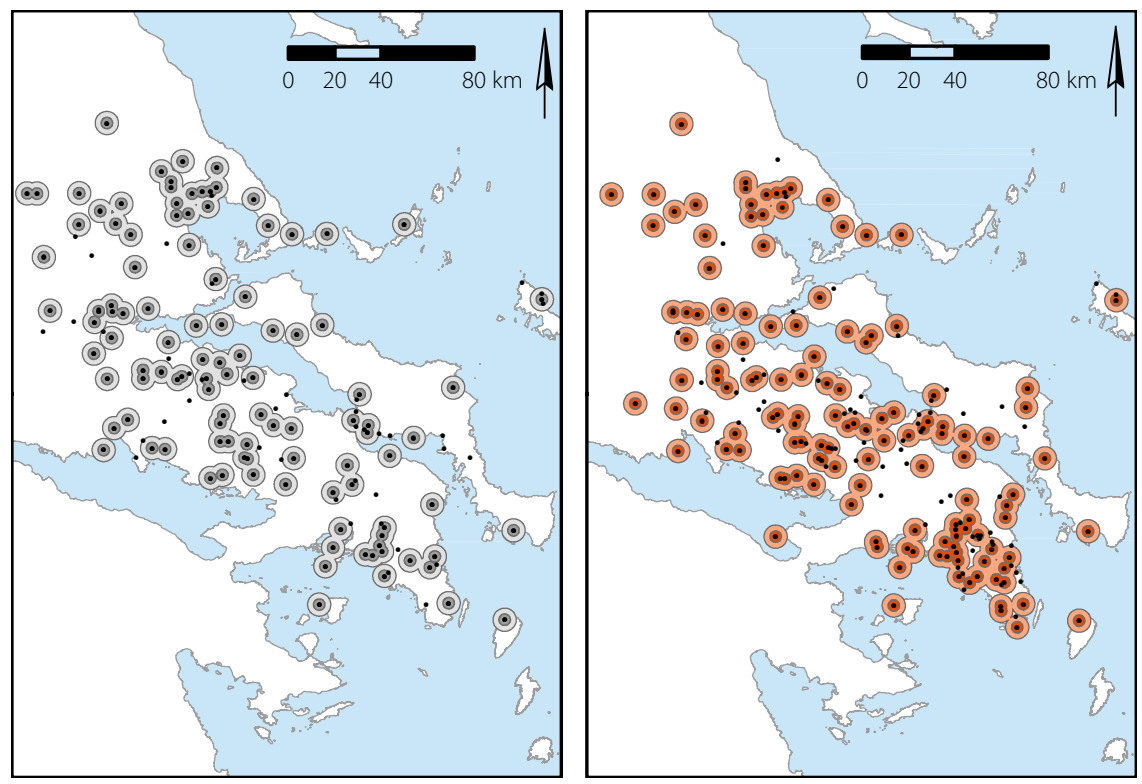

MAP 26. Parallel maps of site catchments in the Prehistoric Iron Age (left) and Protohistoric Iron Age (right), showing the overall site distribution for each period with 2.5- and five-kilometer buffers around communities.

for outward expansion (map 26, left). An influx of new settlement, distributed relatively evenly across the landscape, would have created much more overlap in potential catchments (map 26, right).

In reality, catchment territories would have varied based on site size, population, and the agricultural viability of the surrounding landscape, but a rough model across the study region as a whole nevertheless suggests that the communities of Boeotia and Attica would have interacted much more intensively in this period than in the previous one. It is also significant that central Euboea was already facing settlement pressure in the Prehistoric Iron Age, as were parts of Attica and the plain of Atalanti, which may help to explain their growth and outward-looking character in the Protohistoric Iron Age. Such proximity to each other and such potential for dispute over resource areas may also have historical implications, specifically in the case of a mythohistorical Lelantine war (see further below).

\section{Convergence and Divergence in Settlement Networks}

An immediate effect of the increased number of sites is that the average distance between sites and their nearest neighbors shrinks considerably (see map 25). While certain sites in the network model still have to cross long distances to reach their neighbors (e.g., Zagora, Kefala, Plakari), most-especially in Attica and Boeotiahave many more neighbors close by than they did in previous periods (compare 
maps 15, 19, and 25). The overall change in settlement networks would have had three principal effects:

1. Human interactions intensified across the entire landscape; this was in part responsible for the rapid social change at this time, as communities, craftspeople, and traders came into more intense competition and ideas became increasingly mobile.

2. The nexuses of interaction that formed in different parts of central Greece can be characterized as small worlds, insofar as their most frequent interactions occurred over short distances, but the network distances were quickly reduced through the introduction of only a few new links to join different small worlds. The settlement networks modeled here show interactions between neighbors, which must be viewed as frequent and habitual. In addition, weak ties linked together emergent centers, and regional and interregional land routes stitched together different landscapes

3. The regional networks that emerged within central Greece led to social intensification in new areas, which in some cases led to disengagement from others. This reorganization of interactions led to the reformulation of local and regional notions of identity, which was expressed through aspects of visual and material culture.

More particular patterns are apparent on a regional basis. Attica continued to flourish, as it had done in the Prehistoric Iron Age. The aforementioned increase in the number of sites led to a shift in the nearest-neighbor model, which now suggests some division between eastern Attica and the area of Athens, with Mount Hymettos acting as a divider. That said, the increasing importance of Athens as a hub and production center for Geometric pottery, along with the silver sources of the Lavriotiki, suggests that these areas were quite closely connected. The quadripartite regional interaction between southern Attica, Kea, Andros, and southern Euboea also continues to be significant, evidenced by the presence of Attic (and central Euboean) pottery at Aghia Irini, Zagora, and Plakari (Coldstream 2003, 209-11; Crielaard 2011a, 5; Crielaard and Songou 2017). Connectivity across this zone has important antecedents going back as far as the Neolithic and Early Bronze Age (Tankosić 2011; Cullen et al. 2013). The growth of Athens itself is known from the increased amount of Late Geometric pottery (nearly all unpublished) from the slopes of the acropolis and the number of Late Geometric tombs throughout the city (Papadopoulos 2003, 298-99; Papadopoulos and Smithson 2017; Dimitriadou 2019). Based on the rise in number of graves, Coldstream ([1977] 2003, 109) estimated that the population of Athens increased threefold in the eighth century. Morris (1987, 156-58), however, would attribute at least some of this change to burial practices becoming more democratic and less of a privilege of upper segments of society. The appearance of new sites in the vicinity of Athens 
should not come as a surprise either, and might be viewed in terms of the early development of demes. ${ }^{6}$

The relationship between Athens and the rest of Attica remains difficult to understand in this period, and it continues to be muddled by mythohistorical accounts of synoecism, territorial ambitions, and wars with Eleusis. These typify protohistory in that they have been dated variously to the "age of heroes" (Erechtheus and Theseus), usually associated with the Bronze Age in "real" time, or to the eighth century (Thucydides 2.15.2-3; van Gelder 1991; Morris 1992, 338-39; Lohmann 2010; Bohen 2017). While Athens was certainly the largest and most powerful settlement in Attica at this time, there is not yet any clear archaeological or historical indication of it exercising direct political control over the region. Nevertheless, this period may indeed have been when Athens finally achieved political dominance across Attica, since political integration is one possible response to settlement expansion and population growth-as seems to have been the case in Mycenaean Boeotia, for example. One thing that remains fairly clear in the material record is that Athens and western Attica-including Eleusis and Salamis-were in closer contact than Athens and eastern Attica.

The northern limits of Attica remain poorly understood in the Protohistoric Iron Age, with only a few sites documented: the cave of Pan and the sanctuary of Zeus on Mount Parnes and a few fragmentary finds at Dekeleia (Arvanitopoulou 1959; Mazarakis Ainian 1997, 315; Munn 1989, 240-42; Palaiokrassa-Kopitsa and Vivliodetis 2015). We should note also the sanctuary of Zeus on Mount Hymettos that occupies a liminal space between Athens and eastern Attica (Langdon 1976). This pattern may be the result of people desiring to be closer to emergent centers (such as Athens), rather than located in the relative isolation of a mountainous borderland. This trend is observed especially at Panakton, which boasts substantial remains from the early Mycenaean period, the Postpalatial period, and Protogeometric times, but has nothing from the Geometric period (Munn 1996). Recent intensive survey work in the Mazi Plain has revealed no evidence from any period of the Early Iron Age (Fachard, Knodell, and Banou 2015; Knodell, Fachard, and Papangeli 2016, 2017).

The settlement network of Boeotia changes substantially in the Protohistoric Iron Age (see map 25). Boeotia and Attica are hardly linked at all in the model generated here. They are entirely separated in the nearest-neighbor analysis. In the west, the connectivity model still signals important paths between Eleusis and Plataia. In the east, the connectivity model links Dekeleia and Oropos, although the true orientations of these sites seem to be elsewhere.

The site of Oropos, while sometimes included in Boeotia (Fossey 1988), was considered disputed territory in antiquity (Strabo 9.1.22), and it was often lumped

6. On the historical demes of Attica, see Traill 1975; Whitehead 1986. On their locations and potential territories, see Fachard 2016. 
in with Attica by ancient geographers such as Pseudo-Skylax (Shipley 2010); some archaeological studies have done this as well (see, e.g., Cosmopoulos 2001). In this period, however, as in the previous one, Oropos demonstrates much closer connections to Euboea, as its nearest neighbors are Eretria and Amarynthos; this model is borne out by several aspects of the material record, including settlement organization, cult practices, and craft production (Mazarakis Ainian 2007a, 28; Mazarakis Ainian and Vlachou 2014; see also other essays in Mazarakis Ainian 2007b).

Northeastern Boeotia experienced a significant infilling of the settlement pattern after an apparent gap in the Prehistoric Iron Age. Drosia (Aghios Minas), Glypha, Vathy (Aghios Nikolaos), and Anthedon-all minor sites across the Euripos from Chalkis-were occupied in the eighth century (see map 24). Ritsona appears to have been a hub at the center of these, with some 10 graves dating to the Late Geometric period (Burrows and Ure 1907-8; Ure 1934). This site is considered to be ancient Mykalessos, which, alongside Graia and the other towns of Boeotia, appears in Homer (Iliad 2.494).

In central Boeotia, Thebes experienced significant growth in the eighth century. While archaeological remains, as in other periods, are piecemeal, the Late Geometric shows reoccupation of the Kadmeia and the establishment of organized cemeteries at Aghioi Theodoroi and Pyri, as well as at Aghia Elousa and Tachi. Kountouri (2014) has recently summarized the evidence of Geometric Thebes and argued that scattered habitation in the Protogeometric period had given way to the urbanization of Thebes in the Late Geometric period, complete with sanctuaries at the (later) Temple of Apollo Ismenios and a shrine to Herakles at the Electra Gate. An infilling of the rural landscape occurred at the same time in a pattern not unlike that seen in Athens, although it has been much less intensively researched.

North of Thebes, a string of sites reaches the Euboean Gulf at Anthedon, while another follows land routes to the border zone of the sanctuary of Apollo Ptoios (Ptoion) and Lake Paralimni, where the community at Paralimni Oungra is represented by Protogeometric and Geometric buildings and a rich LG tumulus at Mouriki Kamelovrisi (Farinetti 2011, 371). LG finds in the form of animal figurines at the Kabeirion and Ptoion also speak to wider religious activity in the regional landscape, which, based on proximity, connectivity, and later history, should at this point already be linked to Thebes. It is noteworthy that, with the inundation of the Kopaic Basin after the Mycenaean Palatial period, the area north and northwest of Thebes, previously in the domain of Orchomenos, is now much more closely tied to Thebes.

The densest clustering of sites in Boeotia in this period occurs along a northwest-southeast axis, roughly between Orchomenos and Thespiai, though this pattern may be partly attributed to the relative intensity with which this area, especially the southern portion, has been surveyed (see maps 3 and 4; see also Bintliff, Howard, and Snodgrass 2007; Bintliff et al. 2017; Farinetti 2011). The diachronic pattern and settlement hierarchy also reflect intense activity in this area 
throughout the Early Iron Age, with several significant sites present in the settlement hierarchy: Haliartos and Askra to the east of Mount Helikon; Thisbe and Chorsiai in some degree of isolation on the Corinthian Gulf; and a further cluster around Orchomenos. There are two important points that arise from this patterning. First, the Boeotian communities on the Corinthian Gulf were for the first time self-sufficient in that there were enough nearby communities with which to interact on a regular basis. While this does not mean that they should be viewed in isolation (they should not), it does mean that they did not need to look toward inland Boeotia to the extent that they would have had to do without these local networks. Second, they were well positioned on the increasingly important Corinthian Gulf. Boeotia, with its growing population and its rich land, and with less of a need to look beyond itself, may have become somewhat more self-contained in this period. The network model here suggests a greater amount of internal connectivity with fewer interregional connections; the apparent gaps without significant communities to the northwest and southeast suggest the same. Such a pattern may also be supported by Coldstream's ([1977] 2003, 201) characterization of Late Geometric Boeotian ceramics as the products of a cultural backwater, which displayed Attic, Corinthian, and Euboean influences but did so in a delayed and idiosyncratic way.

Northwest Boeotia, particularly Orchomenos, was a gateway to two major sanctuary areas in this period-Kalapodi to the north, and Delphi to the west. These were without question two of the most important destinations of the eighth century, though they also developed in quite different ways. Kalapodi had long been a significant regional center, while Delphi seems to have grown quite rapidly. Partly in response to these developing sacred landscapes, a number of significant communities were located around these sites, although they were more thinly dispersed than in Attica or Boeotia.

While the number of sites in Phokis grew slightly in the Protohistoric Iron Age, East Lokris and Malis witnessed some marginal decline. While such a drop may not be substantial in and of itself, it is significant in light of the rapid rise in settlements in neighboring Boeotia. The distribution is also significant, following a land route connecting the bay of Atalanti with Kalapodi and, from there, the upper Kephisos valley to the plain of Lamia and the Malian Gulf. The number and proximity of these sites to one another, and their aggregate separation from sites in northern Boeotia, would have led to the intensification of local interaction and may have led also to a decline in habitual interaction with the surrounding areas. Kalapodi continues in its capacity as an important regional sanctuary, although there is a significant shift in the character of ritual assemblages. While intercommunal feasting practices are evident at the site in LH IIIB, LH IIIC, and in the Protogeometric and EG-MG I periods, by MG II and LG, cooking wares nearly disappear, even as the number of cups, kraters, and other drinking vessels grow. These developments are accompanied by an increase in the number of metal 
votive objects, and they are paralleled by contemporary sanctuary sites in Greece (Kaiser, Rizzoto, and Strack 2011, 35-36). This pattern reflects a change in ritual behavior at Kalapodi, where drinking continued to be important but competitive display took on a new character, emphasizing the dedication of high-status goods-namely metals. While Kalapodi does not go on to become the type of panhellenic sanctuary seen at Delphi or Olympia, it nonetheless was an important locus of interpolity convergence in central Greece in the Protohistoric Iron Age, involving especially Phokians and Lokrians, and probably also others from farther afield. So, while East Lokris and Phokis may appear as a somewhat circumscribed network in map 25, Kalapodi and Delphi functioned as major hubs through which significant "weak ties" were maintained to the surrounding regions. A northern Euboean connection is also significant, both in the network model and in a neat axis of oracles to Apollo that run in a straight line from Orobiai (Rovies) to Kalapodi to Delphi, with Orobiai and Kalapodi in clear visual connection with Mount Parnassos (on the little-known sanctuary at Rovies, see Mariolakos et al. 2010).

Turning to the Malian Gulf, the pattern does not differ greatly from the Prehistoric Iron Age (see map 24), although there is significantly greater separation between the area of Lamia and Thessaly, as sites like Ktimeni and Magoula Mati, which may have represented in-between points on land routes linking the two regions, are no longer occupied (compare maps 19 and 25). Settlement sites from the Malian Gulf are almost entirely unknown from this period and must be inferred from the fragmentary cemetery remains mapped here. This can probably be attributed to three factors: (1) the presence of the modern city of Lamia over what is likely to have been the principal site in the region; (2) the lack of widespread systematic exploration; and (3) the heavy alluviation in the plains that would have been ideal for settlement. The sites mapped in the vicinity of Lamia are cemeteries, but the presence of settlements within reasonable walking distance can safely be assumed.

The concentration of sites located on the Malian Gulf and the strait of Oreoi (see map 25) reinforce the strategic location of this area. The linear arrangement of sites also makes interactions across water likely. Kainourgio, Achinos, and Lichas Kastri form a neat triangle on the western end of the strait of Oreoi, where they could have controlled access between the northern Euboean Gulf and the Pagasetic Gulf and the wider Aegean. The relative isolation of Theotokou in southern Magnesia and the new settlement at Skiathos (a transplant of the Prehistoric Iron Age site of Kefala) also suggest connections to Oreoi or Kerinthos (see map 25).

As the northernmost frontier of the Euboean Gulf interaction zone, the sites around the Pagasetic Gulf remain an important interface between northern and southern Greece both by land and by sea. In terms of habitual interactions, they can be viewed as relatively self-contained, although important connections to other small worlds would have been maintained by significant nodes at Theotokou and Halos. 
The modeled connections of the northern Euboean Gulf do not differ markedly from those exhibited in the previous period (compare maps 19 and 25). Of course, this is because this model is dependent on the settlement pattern, which also does not vary widely between the Prehistoric Iron Age and the Protohistoric Iron Age. However, wider sets of interactions are certainly visible in the material culture of Thessaly, especially around the bay of Volos: Attic and Euboean influences are evident in the painted pottery; Thessalian sanctuaries exhibit Macedonian ornaments in bronze; and there are commonalities between handmade pottery found in Thessaly and Macedonia (Coldstream [1977] 2003, 206-9). Thus, the material culture largely suits the geographical position of Thessaly as an important interface between central and northern Greece. And in this period, Thessaly, more than other regions, was looking increasingly to the north.

Some consideration must be given to the question of why this rapid change in settlement pattern occurred at the same time as what must be considered a settlement shift on a much wider scale-the foundation of settlements overseas (apoikiai). Trade interests and population pressure are the most common explanations for the establishment of colonies overseas (see, e.g., Boardman 1980; Tsetskhladze 2006, 2008). Trade interest is an obvious prime mover, and the Phoenician expansion (see chapter 5, pp. 180-84) is followed closely by the Greek case. Moreover, the farsearching quest for metals was nothing new in the Greek world, having roots in the Mycenaean period (chapters 3 and 4). Nevertheless, the scale of overseas settlement in the eighth century was something new. The expanding site numbers may suggest population pressure, but the regions of central Greece whose site numbers expand most (Attica and Boeotia) were not involved in colonization at this stage. Moreover, even these regions are not likely to have had populations that put serious pressure on the landscape until the Classical period (Bintliff 1997, 3). Expanding site numbers in Attica and Boeotia may therefore reflect an intensification of land use at home, while other polities looked to expand their resource base through apoikiai.

The specter of climate change has long loomed in the background of the major shifts in settlement of the eighth century. Camp (1979) argued that several wells in Athens, which were either redug or went out of use during the eighth century, may indicate a period of drought and a lower water table. Accordingly, he suggested a revision of the land-hunger hypothesis for colonization, arguing for lower agricultural production rather than simple population growth as an impetus for settlement overseas. Recent paleoclimatic studies have indicated a drying trend in both Italy and the Aegean beginning in the eighth century (Finné et al. 2011, 3158). This trend coincides roughly with a rapid decline in total solar irradiance on a global scale (Steinhilber, Beer, and Fröhlich 2009, 3), which would have affected plant growth and therefore agricultural output. The degree to which these factors would have influenced ancient agricultural practices is debatable, and the Mediterranean climate is notoriously variable, so these factors need not indicate that a drought in Athens or elsewhere in central Greece took place. But recent studies do force us 
to consider the possibility. At the very least, climatic instability is a destabilizing factor, especially in the already vulnerable microecologies that characterize the Mediterranean (Kenett and Marwan 2015). In this case, climatic instability may have provided an impetus for change in agricultural regimes and the pursuit of new settlement strategies, which varied by region. ${ }^{7}$

Politics may also shed light on shifts in the settlement pattern. Small (2019, 126-29) suggests that "community fissioning" was a prime mover in the establishment of apoikiai, wherein competing elite factions (families) from Greek communities split off to establish settlements overseas, sometimes involving cooperating groups from other communities. According to this scenario, elite access to political power in new arenas was the principal motivation for new settlement; this is supported by the detailed descriptions of kin-relationships that appear in early accounts of colonization (see also Osborne 1998).

A mixed explanation, then, may be considered whereby individuals and groups living in certain parts of Greece already involved in long-distance endeavors sought to solidify footholds abroad as a sort of insurance in response to climatic variability. At the same time, other regions (especially fertile ones such Boeotia) expanded settlement in the agriculturally rich areas around them or pursued agendas of political integration (this may also be the case in Attica). Thessaly, with its vast tracts of agricultural land and its slightly different microclimate, may not have been threatened at all by climatic shifts, and the decline in settlement numbers there may in fact represent an unrelated consolidation of population. Whatever the underlying environmental or demographic factors, the landscape shifts in the eighth century have a distinctly political character to them, and they involved a complex set of human decisions to pursue new settlement strategies and modes of social organization.

\section{Political Landscapes at Home and Abroad}

Throughout the eighth century, a series of events took place in central Euboea that had far-reaching effects. The destructions at and the eventual abandonment of Lefkandi, along with the foundation and growth of Eretria, suggest disturbance, and later literary testimony tells of a large-scale conflict between the Chalkidians and Eretrians, which involved allies from all over the Greek world and which changed political relationships in various places in the Aegean, Sicily, and Italy (Thucydides 1.15). While many uncertainties surround the specific events on the Lelantine Plain in the eighth century, especially with regard to the literary tradition, they are worth revisiting in light of the archaeological, historical, and geographical context. Moreover, the Lelantine Plain provides a case study in how

7. A series of recent studies have focused on human responses to climate change through the use of multivariable models incorporating climate data with proxies for settlement, population, and societal stability (see, e.g., Weiberg et al. 2019; Vidal-Cordasco and Nuevo-López 2021). 
multiple lines of evidence converge in the landscapes of the Protohistoric Iron Age to offer new perspectives on archaeological and historical questions.

The density of settlement in central Euboea, specifically around the Lelantine Plain, was greater in the Pre- and Protohistoric Iron Age than anywhere else in the regions surrounding the Euboean Gulf, with the exception of the immediate vicinity of Athens. This can be explained rather simply by historical and geographical factors: the area had been a hub at least since the Postpalatial Bronze Age, partly on account of its location, which afforded control of access between the northern and southern Euboean Gulf, and partly on account of its proximity to the fertile Lelantine Plain. The territorial catchments and nearest-neighbor network model also suggest rather intense interactions between these communities (see maps 25 and 26). With such intense interactions sustained over long periods of time, cycles of cooperation and conflict should come as no surprise.

Historians have long grappled over a mythohistorical event (or series of events) called the Lelantine War. ${ }^{8}$ The most comprehensive account comes from Thucydides (1.15), who records a conflict between Chalkis and Eretria over the Lelantine Plain, noting that each of these cities had allies from various parts of the Greek world (see also Herodotus 5.99.1). Hall (2007, 3-8) has been skeptical regarding the question of what these references can tell us about a historical conflict, wondering even if such a conflict ever actually took place, and he has argued that there is little to suggest that the tradition of the Lelantine War was based on actual events. Other authors have been more optimistic about both the utility of the historical record and its usefulness in reconstructing interactions between early Greek polities (Coldstream [1977] 2003, 200-201; Walker 2004, 162; Lane Fox 2008). Despite such long-standing (and divergent) viewpoints, the question of the Lelantine War is worth reconsidering here from a landscape perspective.

The literary tradition concerning this conflict did not emerge ex nihilo. Moreover, the archaeological record, while not capable of "proving" the validity of historical records, is not in disagreement with them. The physical geography lends further insight into historical accounts and the interpretation of archaeological remains. All these factors should be viewed together in interpreting this storied landscape.

I make three interrelated arguments here: (1) that the inhabitants of Lefkandi moved to the location of Eretria gradually between 850 and 700 BCE; (2) that this move was the result of building tensions derived from shared circumstances on local, regional, and trans-Mediterranean scales that culminated in a conflict between Chalkis and Eretria; and (3) that a reorganization of the local landscapes and long-distance activities alleviated this strain and led to divergent trajectories for these two Euboean city-states.

8. Modern scholarship on the Lelantine War has not been intensive, but interest has cropped up at numerous points over the last century (e.g., Burn 1929; Bradeen 1947; Donlan 1970; Bakhuizen 1976, 34-36; Lambert 1982; Parker 1997; Knoepfler 1997; Walker 2004, 162-71; Hall 2007, 1-8, 20-21; Christodoulou 2015; Fachard and Verdan, forthcoming). 
Strabo (10.1.10) presents the idea of an Old Eretria, the interpretation of which has troubled archaeologists and historians of Euboea for some time now. One common interpretation of this reference, in combination with the occupational history of Lefkandi, is to suggest that this site was Old Eretria and that its abandonment may be linked to a territorial conflict with Chalkis (see, e.g., Popham 1980; Walker 2004, 73-89). ${ }^{9}$ In fact, it seems that Strabo never went to Euboea himself, so he may not be the most reliable source. If we remove the notion of "Old Eretria," the occupational and political history of central Euboea in the eighth century BCE are much clearer.

The local topography can help shed some light on this matter (map 27). The Lelantine Plain is clearly visible in the modern topography as some 30 square kilometers of agricultural fields, which are well watered by the Lelas River. The riverbed runs through the center of the plain, with Chalkis and Lefkandi nearly equidistant on either side (Lefkandi, on the east side, is slightly closer). Other sites of strategic importance are positioned at its corners at Nea Lampsakos, Dhokos, and Phylla. The southwestern foothills of Mount Olympos form its eastern border, and a narrow (less than one kilometer) strip of the Eretrian Plain runs along the coast until it opens up to a fuller agricultural plain east of Eretria, situated some ten kilometers to the east of Lefkandi. Eretria is about eight kilometers away from the eastern edge of the Lelantine Plain, putting it well outside the putative territorial catchment for agriculture (see map 26). Anything to the east of Eretria would be even further removed from the capacity to exploit and control such a territory (a point that leads to the rejection of Amarynthos or Magoula as potential candidates for an Old Eretria in such discussions). Of course, distance alone does not preclude territorial interest or control, but proximity matters, especially when a potential competitor (Chalkis) is located much closer to the land in which there was a mutual interest. Another argument for the importance of proximity can be found in the Bronze Age, when the highly centralized Mycenaean palaces, which sought to maintain hegemony over significant amounts agricultural land, often at some distance, were careful to station secondary centers in prime agricultural areas, as well as at other points of strategic importance (see chapter 3 ). The crucial point here is that control over agricultural territory is not

9. This question also relates to the identity of Lefkandi, the ancient name of which remains unknown. Strabo's account seems to place Old Eretria at the site of Eretria itself, though some have argued that Old Eretria should be Lefkandi (Popham 1980). Bakhuizen (1976, 7-13) argues that Lefkandi should be considered Old Chalkis. Powell $(1991,15-16)$ suggests that Lefkandi may have been Euboean Kyme, citing an unpublished talk by E. Touloupa. Others would place Old Eretria to the east, with Amarynthos or Magoula as possible locations (Boardman 1957, 22-24). One attractive argument for the ancient identity of Lefkandi is Argoussa or Argoura, from the root $\alpha \rho \gamma$ - meaning "white" or "bright"a possible reference to the white cliffs that characterize the site (Knoepfler 1981, 309-12; Fachard and Verdan, forthcoming). This is also the root of the eighteenth-century toponym: Lefkandi, from $\lambda \varepsilon v \kappa o$,

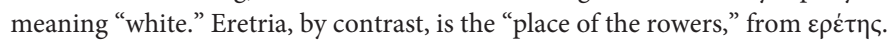


feasible in the face of direct competition without maintaining close proximity or presence through a proxy.

The occupational histories of Lefkandi and Eretria lend the most credence to the argument that Eretria was a foundation of Lefkandi. It actually matters little for this argument whether the "Old Eretria" referred to by Strabo was a specific allusion to an older part of Eretria, Lefkandi, or somewhere else. Based on the archaeological evidence of settlement, the following narrative applies: Lefkandi flourished throughout the LH IIIC, Protogeometric, and Subprotogeometric periods, albeit with intermittent destructions (see, e.g., Sherratt 2006a; Popham and Sackett 1980). Beginning around 825 BCE there seems to have been a general decline in population at Lefkandi, based on numbers of burials and fewer settlement remains (though admittedly only a small section of the settlement has been excavated). The first traces of settlement found at Eretria date to the same period, in the form of burials with ceramics that suggest influences from both Lefkandi and Athens (Mazarakis Ainian 1987, 3; Verdan, Kenzelmann Pfyffer, and Léderrey 2009). Walker $(2004,92)$ follows Popham and Sackett (1980) in suggesting that the evidence from Lefkandi and Eretria indicates an attack on the former, followed by decline and a population movement to the latter, as Lefkandi remained an outpost positioned to exploit the Lelantine Plain. Occupation at Lefkandi seems to cease around $700 \mathrm{BCE}$, although a handful of Archaic and Classical sherds have been found at the site (Sackett et al. 1966, 61).

This sequence of events could be interpreted differently, but in this case the archaeological record seems fairly clear. More nuance might be gained by viewing this evidence in its broader temporal context. A number of destructions at Lefkandi from the LH IIIC period through the Early Iron Age indicates a long history of conflict at the site, which could have built up to a larger-scale conflict that eventually entered historical memory as the Lelantine War. This possible scenario is not unlike the one at Troy, where multiple destructions have been documented archaeologically, and may have coalesced into an eighth-century tradition of the Trojan War (see, e.g., Mac Sweeney 2018, 32-36).

There are several potential reasons that people from Lefkandi began moving to Eretria as a satellite settlement: population growth, decreased agricultural yield, or increasing competition over the Lelantine Plain. Eretria was well positioned on the west side of the Eretrian Plain, was close to Lefkandi, and at the same time afforded access to the coastal strip between the two sites. Moreover, Eretria offered intrinsic advantages, with a high acropolis and deep harbor. The cessation of settlement at Lefkandi in the Late Geometric period and the rapid expansion of settlement at Eretria combine to make about as direct a suggestion for population movement from one proximal site to another as one can hope to see. It is also possible that a closer connection between Amarynthos and Eretria was developing at this time, since in historical periods the sanctuary of Artemis Amarysia-on the east side of the Eretrian Plain-is known to have been under Eretrian control. This spanning of the Eretrian Plain reflects a clear shift in agricultural interests and priorities to 


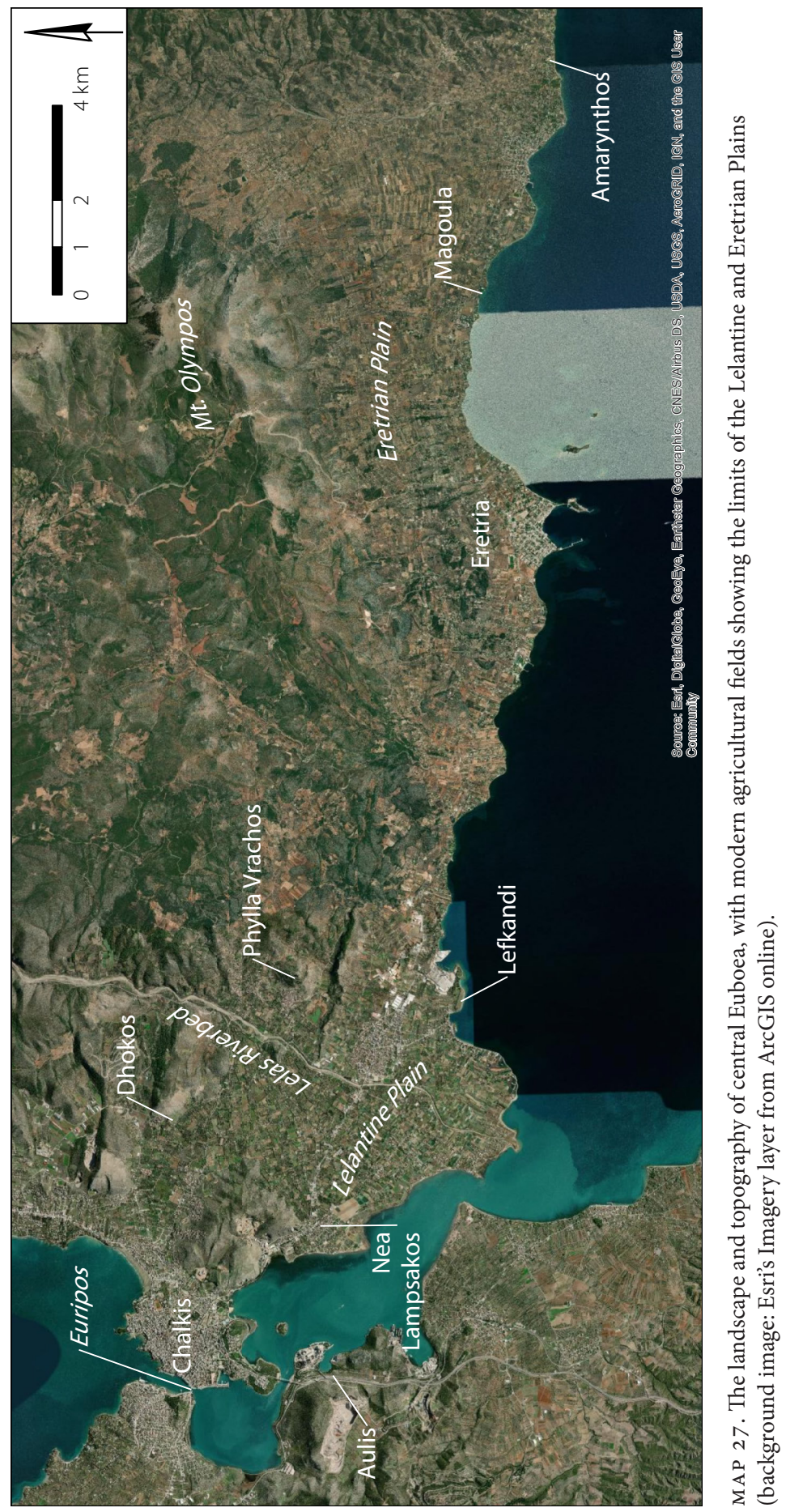


the east, away from the Lelantine Plain and toward other areas that would eventually comprise the territory of Eretria.

There are further similarities between Lefkandi and Eretria that support this settlement history. The warrior burials in the West Quarter of Eretria are suggestive and at times have been pointed to as the heroized dead of the Lelantine War (Bérard 1970; Walker 2004; Christodoulou 2015). The triangular heroön is considered the culmination of this tradition, and it has been dated to the late eighth or early seventh century (Bérard 1970; Blandin 2007). The burials are similar in content to those of the Toumba cemetery at Lefkandi, and they occupy a similar topographic position in relation to the main settlement. Both are on the western edge of the settlement, have conspicuous funerary markers, and face the rival polity of Chalkis. This may suggest the deliberate introduction of place-making practices at Eretria, where the customs of elite warrior burials were preserved in the Geometric cemeteries in the West Quarter, representing efforts to memorialize and heroize elites and to define the boundaries of the community. At the same time, a building of particular importance, the Geometric Temple of Apollo Daphnephoros, recalls the long, apsidal plan of the Toumba building, and it exhibits-in the Late Geometric period-significant evidence for feasting activity rather than an assemblage characteristic of later temples (although note that this apsidal form is not unusual for the period in and of itself: see Mazarakis Ainian 1997; Verdan 2013, 208-11). Unfortunately, we lack comparative evidence from Chalkis, because of the highly fragmentary nature of the archaeological record, which was largely destroyed and obscured by centuries of later occupation.

Between the settlement evidence and the historical tradition of a war between Chalkis and Eretria, it is not difficult to imagine some sort of conflict that forced the change in settlement location. Yet complications with the historical record remain. Strabo in fact seems to give the location of Old Eretria at Eretria, claiming that the site was destroyed by the Persians. This makes sense, but the distance he gives from Athens would put Old Eretria to the east, near the location of Amarynthos. We know well that Eretria had been in its current location at the time of the Persian Wars, so Strabo is already off the mark and internally inconsistent, which should come as no surprise. Confusion, internal inconsistency, and outright error in ancient sources must be allowed for, especially when historical context, archaeological evidence, and geographic realities support different stories, as is the case here. Yet at the same time these stories may have roots in reality, even if certain details are better rejected. Ultimately, the questions of whether something called Old Eretria existed and where it was located are much less relevant than what the archaeological record tells us: that occupation at Lefkandi ceases after a long history of conflict at the same time settlement at Eretria intensifies.

Such a case presents an opportunity for a combined historical and archaeological analysis of political relationships on multiple scales-within a local agricultural landscape and spanning the Mediterranean. Pithekoussai, on the island of Ischia 


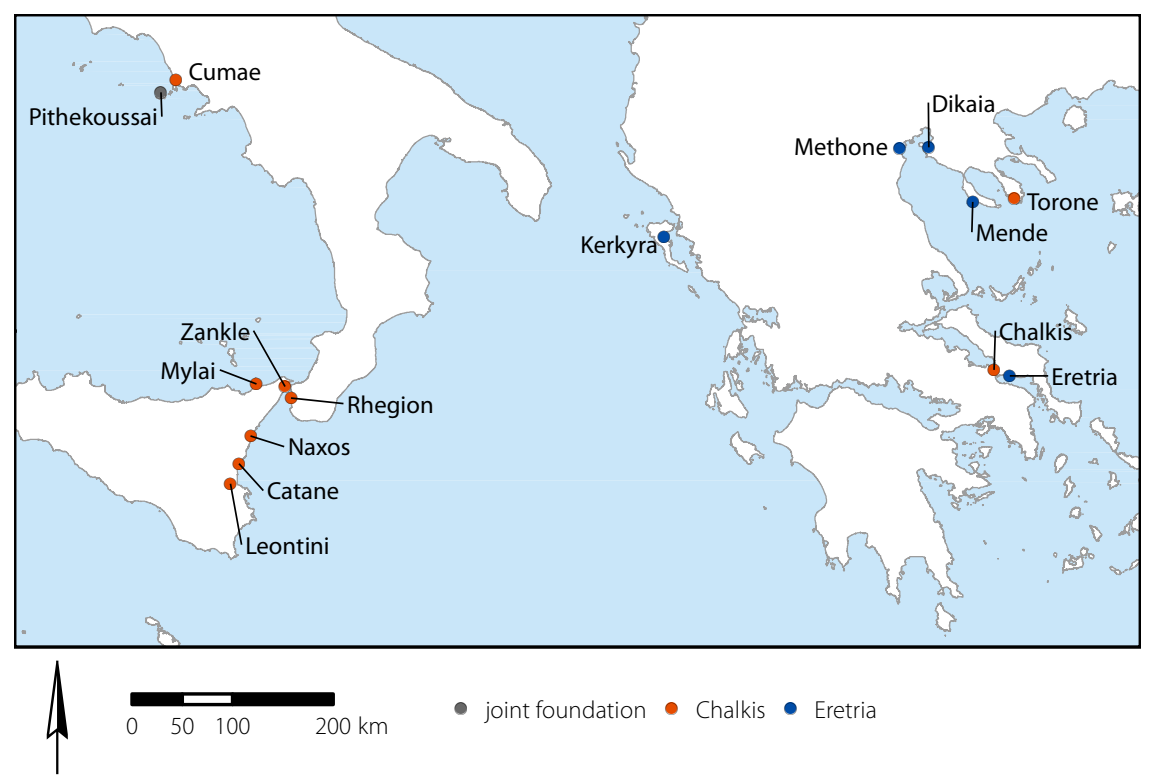

MAP 28. Euboean colonies, showing affiliations with Chalkis or Eretria, based on historical sources (note that some are joint foundations with other cities as well; for further details and historical sources, see Osborne 2009, 114-15; Knodell 2013, 298).

just off the west coast of southern Italy, is the earliest evidence we have for permanent Greek settlement overseas (Buchner and Ridgway 1993). Livy (Ab urbe condita 8.22.5-6) relates that the settlement at Pithekoussai was a joint foundation between Chalkidians and Eretrians. Not long after this, the Chalkidians are said to have founded Kyme (Cumae) on the adjacent mainland, and a long string of Euboean colonial foundations followed (map 28). Walker $(2004,142)$ argues that Pithekoussai was a joint foundation between Chalkis and Eretria, then war broke out on the Lelantine Plain, causing the Eretrians to expel the Chalkidians from Pithekoussai; the Chalkidians then founded Kyme on the Italian mainland. This site had no clear relation to a Euboean Kyme, which may not have existed until the modern period (Brodersen 2001). After the earliest foundation at Pithekoussai, the long-distance interests of Chalkidians and Eretrians declined and diverged considerably, though both groups later remained interested in some of the same general areas, such as the northern Aegean, although never the same precise locations (Tiverios 2008).

Thorough accounts of Euboean colonial activities can be found elsewhere (see, e.g., Crielaard 1996; Tsetskhladze 2006, 2008). The important point here is the pattern - the split that can be observed between Chalkidian and Eretrian interests that parallels local developments on the Lelantine Plain, reflecting a reorganization of networks across significant distance, based on a local breakdown of relations. 
Despite this conflict and split in interests, reconciliation between Chalkis and Eretria may soon have been reached, as the overseas interests of Eretria seemed to shift to the north Aegean, which was most accessible through the Euripos, under the control of Chalkis. The explosion of colonial activities abroad in the Euboean case, and shortly after from other parts of Greece, is a prime example of global emergence from local interactions (see Malkin 2011, 210). Moreover, network growth continued in the western Mediterranean as "Euboeans" from Pithekoussai struck out to settle new locations. In these cases, it is not so much the agency of Euboeans in Euboea that affects expansion in the central Mediterranean after the initial settlement but the network growth that is independent of any mother city. Nevertheless, ties to the mother city were likely still felt and considered important in identity-forming self-ascription-that is, the creation and reification of identity markers in a world increasingly filled with different cultural backgrounds and political affiliations. The resultant imbroglio of interactions and material expressions has been preserved in the media revolution that coincided with this explosion of activity in both the Euboean Gulf and farther afield (see further below, pp. 215-25). The reorganization of the religious landscape across central Greece played an important role in mediating these shifting political relationships.

\section{Sacred Landscapes as Hubs of Mediation}

The growth of regional, and eventually panhellenic, sanctuaries in the eighth century forms another piece of network architecture in the revolutionary developments of the eighth century. Like colonization, this phenomenon is well known, especially through the seminal work of de Polignac (1994, 1995; see also Malkin 1987, 2011; Antonaccio 1995; Morgan 1993; Osborne 2009; McInerney 2011). The impact of religious practices on political and territorial developments can be seen clearly in the material record from local, regional, and panhellenic sanctuaries. Like other aspects of the early Greek landscape, such forms have roots in earlier periods but proliferate in this one.

On the level of individual communities, feasting events at "sacred houses" seem to have been important exercises in group formation, evolving out of similar practices in the Prehistoric Iron Age and Postpalatial Bronze Age (Whitley 1991, 62-64). In Attica, these were probably associated with elite kinship groups in different parts of the region-namely, Athens, Eleusis, and Thorikos-and were sometimes associated with local heroes (Alexandridou 2018; van den Eijnde 2018). In Athens alone several such buildings have been identified, some more confidently than othersat Plato's Academy, on the Areopagus, in the vicinity of the Classical Tholos at the Agora, and at Herakleidon Street, close to the Piraeus gate (Alexandridou 2018). The mortuary record offers a window into another type of sacred landscape, although this is extremely uneven across regions. In Attica, we can see the emergence of elite kinship groups in necropoleis, which may reflect competition between factions within a community (Alexandridou 2017). Mazarakis Ainian (1997, 384-85) argues that places of power would eventually evolve from rulers' dwellings into 
institutionalized religious structures such as temples, where the community as a whole would come together. Again, however, variation is probably the rule. While there are shared attributes between rulers' houses and early temples, this probably has more to do with the conception of temples as monumental houses (of gods). At any rate, one trend of the eighth century is to see sacred spaces increasingly develop as places of mediation within communities, a trend that is paralleled by sanctuaries between communities and even between regions.

On a local level, tomb cult was a defining practice in the Early Iron Age. While ancestor veneration, and perhaps even worship, may have had Prehistoric Iron Age precedents at places like Lefkandi, the tholoi of Thessaly, and the chamber tomb cemeteries of Phokis, the practice seems to become widespread in the Late Geometric period (Antonaccio 1995). In Attica and Boeotia, this seems to come out of a renewed interest in the Bronze Age landscape (Antonaccio 1994). This interest in the past and the creation of places of memory and ancestral significance in the landscape should be seen in relation to the increasingly close proximity of archaeological sites to one another and the need to establish territorial claims. I do not, however, wish to reduce this aspect of Greek religion to an economic argument. Bronze Age and Prehistoric Iron Age remains indicate that there had long been an interest in the past-people built on the same places and in some cases reused tombs, whether they belonged to relatives or not. Memories, of real or imagined connections, would have been tied to these places, which would have been habitually encountered in the course of daily life. What we see intensifying in this period is not necessarily interest in the past but material engagement with it. With the rapid infilling of the settlement pattern, it became increasingly important to leave material marks on places of collective memory and significance. This interest in the past (and in creating pasts) coincides with, but does not necessarily result from, literary concerns in the same vein: oral traditions and epic poetry having to do with an "age of heroes."

This period also saw shifts in the character of regional sanctuaries (see also Eder 2019). From the Palatial period onward, sites such as Kalapodi had functioned as regional mediators of interaction between various peer communities. While political relationships were clearly present, they were embedded in religious practice. Traces of cult activity have been found at numerous other sites but rarely to a degree that makes them stand out. This changed dramatically in the eighth century, as sanctuary dedications increased dramatically, even as the presence of luxury items (chiefly metals) in graves declined (Snodgrass 1980a, 53; Morris 1987, 141). This trend is best interpreted as the result of increasing interaction between individuals and polities on a regional scale, which occurred at sanctuary sites as competitive practices of dedication. These practices accompanied the athletic competitions for which these places were now the preeminent sites. ${ }^{10}$

10. While athletic competitions can be observed in the Bronze Age, a distinct association with regional sanctuaries is documented beginning in the eighth century. 
In the Prehistoric Iron Age conspicuous consumption was largely tied to individuals, and operated on a local scale, which can be seen in wealthy burials at places such as Athens and Lefkandi. The eighth century witnessed a marked shift in this behavior, mainly in the dedication of large bronze tripods-symbolically charged items made of a valuable commodity - that were set up in highly visible locations of ritual and political significance that did not belong to any individual or polity but were places of mediation and competition between them. Papalexandrou (2005) has written extensively on the tripod as symbolic capital and its role in the visual poetics of power that played out in early sanctuaries, especially at Olympia and Delphi. Tripods also functioned as both symbolic and economic stores of value (Papadopoulos 2012). Moreover, a shift in the deposition of arms from local graves to regional sanctuaries has been taken to mean that military force shifted from the domain of the individual to the community and its political apparatus: this was an important marker also in the development of early poleis (Snodgrass 1980a, 52-53, 99-100; Morgan 1993, 27).

Extensive discussion of the role of regional sanctuaries in polis formation and the origins of Panhellenism can be found in the references above. Their importance here is as major nodes in a network architecture that spanned various spatial and social scales. Local sanctuaries and tomb cults served to reinforce boundaries and demarcate territory through ancestral links to the landscape. Regional shrines served as places of common ritual practice, mediation, and competition between local authorities. At the same time, regional cults were both codified and dispersed throughout the Mediterranean-for example, via the worship of Artemis along the Euboean Gulf or the dispersal of elements of Euboean cults across the Mediterranean (Cole 2000; Boffa and Leone 2017; Kowalzig 2018). During the eighth century, the networks of Olympia and Delphi grew especially quickly, and they emerged as the first Panhellenic shrines, whose importance and roles as mediators were highlighted through the introduction of formal competitions (both artistic and athletic) and oracular functions. Perhaps most importantly, they brought people together from across great distances, based on shared aspects of religious and linguistic identity. This is another example of scale-free network growth, where nodes (Greek polities) preferentially attached to two of many possible regional centers (Delphi and Olympia), causing accelerated network growth over a relatively short period of time. It is also an example of multidirectionality and pulsation in small-worlds scenarios, as habitual meetings in certain hubs brought people and images into contact with one another and then flung them back out again. That is, the network contracted on a single place, and then was released outward again after participants came into contact any number of people, things, and ideas that they normally would not have encountered.

That this network pulsation occurred at the same time as the first large-scale colonization movements is significant, although it is difficult to discern a simple causal relationship between them. The most likely explanation is that regional 
sanctuaries, such as Kalapodi, had been in use since the Bronze Age, although activities at them intensified and formalized in an increasingly mobile eighthcentury world. Habitual encounters with difference created a need to reinforce commonalities, and the venues for this engendered competitions through which independent polities, represented by individuals, strove to "outdo" each other through acts of direct competition and conspicuous consumption. A clear example of how this took place in the Geometric period can be found in the dedicatory tripods with figural attachments in the form of horses, birds, and humans (Papalexandrou 2005); these fueled the quest for metals and at the same time promulgated an iconography that was eventually adapted to other forms of figural art. Sanctuaries thus provided the hubs that greatly reduced the physical and conceptual distance that images, motifs, and innovations needed to travel to reach anywhere else in the growing Greek world. In the context of this competitive and highly charged network, which was capable of spreading ideas over great distances very quickly, we can describe a media revolution that changed the face of material, visual, and oral culture.

A MEDIA REVOLUTION:

\section{WORDS AND IMAGES ON THINGS}

The invention of the Greek alphabet and the reemergence of figural art on pottery were among the most significant developments of the eighth century. The spread of these innovations was particularly rapid, and they had the added effect of carrying messages with them that were independent of utility, style, and technological knowledge. Much has been written about whether one of these innovations preceded the other-especially about figural art as a response to Homer (e.g., Carter 1972; Langdon 1993; Powell 1997; Snodgrass 1998). Langdon (2008) in particular has shown that figural art probably should not be seen as a direct response to Homer. I argue that writing and figural art emerge in the eighth century as part of the same phenomenon, representing new concerns with display and self-presentation, as well as with establishing permanence through recording on things the thoughts and expressions of a heretofore predominantly oral culture. This new materialization of social relations had important implications in an increasingly interactive world.

\section{Technology Transfer from Potters to Poets: \\ The Invention of the Greek Alphabet}

The innovation of Greek writing in the eighth-century Mediterranean was distinct from other writing systems in the circumstances of its creation, its rapid diffusion, and its far-reaching effects. ${ }^{11}$ In this section I examine what the earliest writing

11. The literature on the introduction of alphabetic writing to Greece is extensive. See, most recently, Janko 2015; Papadopoulos 2016b; Clay, Malkin, and Tzifopoulos 2017; Whitley 2017; Pappa 2019; 
in the Greek world does rather than what it says or what its linguistic roots are, though these concerns are certainly related. Whitley (2017) provides a recent and a compelling case for archaeological approaches to the history of early Greek script, focusing on its materiality and regional variability rather than on its relationship to literacy or universality across the Greek world. From a geographical perspective, the Euboean Gulf was an important conduit for this innovation, with the Euboeans themselves probably playing a central role. More specifically, the rapid proliferation of early Greek writing allows us to work backward to say something about the societies and circumstances under which it was introduced. ${ }^{12}$

The loosely organized village societies of the Prehistoric Iron Age did not use writing as an administrative technology. Writing systems of the Bronze Age were adapted specifically in the centralized political context of the palace, with an interest in controlling access to and the use of writing. By contrast, our evidence for the earliest use of writing in the eighth century BCE comes from three social contexts: pottery workshops, trade goods, and communal drinking events (on the latter, see especially Węcowski 2017).

The invention or adoption of a writing system constitutes a media revolution in nearly any cultural context in which it occurs. In this case, when widely visible and accessible, writing fundamentally changed the way people interacted with each other and the world around them: it gave permanence and portability to speech through the introduction of a new medium to interpersonal and intersocietal relations-words inscribed or painted on things. This can also be seen as a technological innovation, making use of various tools, materials, and specialized knowledge (Ong 1982, 81-82). Writing must therefore be learned and taught, adding a significant interactive element to the process. At the same time, however, describing writing as technology has its drawbacks, as to do so distances script

Bourogiannis 2020; Steele 2020. Classic studies of early Greek dialects and alphabets are by Kirchhoff (1887) and Jeffrey, the latter of which has been recently updated with a supplement by Johnston ([1961] 1990). There are several recent overviews as well (Woodard 1997, 2010; Wachter 2006; Voutiras 2007; Horrocks 2010; Węcowski 2017). Powell (1991, 2002, 2009) has dealt with script invention extensively, especially its relation to Homer and oral poetry. Recent work by Sass (2005) puts the invention of the Greek alphabet in its wider West Semitic context and argues for a much earlier adoption, which is an increasingly common feature of linguistic arguments (e.g., Waal 2018). A good deal of important, recent work has looked at early scripts from a comparative perspective, both for alphabetic scripts (Boyes and Steele 2020) and in earlier periods in the Aegean (Steele 2017). Beyond script invention, serious consideration has also been given to the impact of literacy on a heretofore oral culture (Ong 1982; Havelock 1986; Thomas 1992).

12. The Phrygian writing system was invented around the same time, and it has many shared characteristics with the Greek alphabet, including vowel use (Brixhe and Lejeune 1984). Recent chronological developments at Gordion (Rose and Darbyshire 2011), however, call into question the standard argument that Phrygian is derived from Greek, and may suggest a Phrygian precedence of the alphabet, yet this is far from definitive (Brixhe 2002; Sass 2005, 146-49). For the significance of the northern Aegean as a potential crossroads of the Greek and Phrygian alphabetic traditions, see Papadopoulos (2016b), who also notes the close similarities between Phrygian and Eretrian scripts. 
from other ways of transferring meaning (Houston and Stuart 1992, 590). While writing involves the technical acts of other technological practices, it is ultimately a communicative, semiotic system that varies based on form, context, production, and response (Houston 1994, 28). Thus, writing cannot be viewed in strictly technological terms, although technological metaphors remain useful in considering the skill, craft, and transfer of knowledge required for its spread and deployment.

Communications technologies have dramatic impacts on the pace of social change in human societies (see, e.g., Robinson 2007; Powell 2009; Gnanadesikan 2009). The first writing appeared in the second half of the fourth millennium BCE in Sumer, which saw the emergence of the first state-level societies not long after. In the roughly 5,500 years since then the scale and complexity of human societies have increased in a way that would have been inconceivable to ancient Sumerians. In the 5,500 years before the invention of writing relatively little had changed, at least when compared to what came after. The long-term consequences of this revolution in human interactions are well worth considering in their particular cultural and historical circumstances, especially after a sustained period of the disappearance of writing (see also Baines, Bennet, and Houston 2008).

Greek alphabetic writing appears to be the first writing system that was not invented for the purpose of state or religious administration. It is also one of the first writing systems to give vowels separate phonetic designations, in order to encode human speech in words comprised of individual letter sounds rather than through syllables or consonants alone (Powell 1991, 115-18). In West Semitic alphabets, for example, words were written as a series of consonants, and it was left to the reader to fill in the vowels. This is not a problem if the reader knows the language, but it makes it more difficult for others to use and to adapt such a system. Powell (1991) has argued that this innovation was made by a single man from Euboea (the "adapter") specifically for the purpose of recording hexametric poetry. ${ }^{13}$ While the motives and processes of adaptation are likely more complicated than this, the desire to write in this way does not seem to have had administrative roots.

The introduction of vowels was a practical matter in adapting the Phoenician script to record Greek, and it had great consequences later on. For example, the adaptability of the system, which encodes consonantal and vowel sounds separately, makes it highly flexible and accounts for its diffusion and further adaptation to record a variety of other languages. The addition of vowels made it possible to write sound and speech directly, resulting in a rapid diffusion around the Mediterranean. The Greek alphabet, in particular the Euboic alphabet, formed the basis for the Etruscan alphabet, various other Old Italic scripts, and eventually Latin. At the same time, the rapid development of epichoric alphabets, which were in place

13. This idea goes back to Wade-Gery $(1952,9-14)$. For a recent summary and critique, see Whitley (2017, 76-82). 
by the seventh century $\mathrm{BCE}$, show the regional creation and concentration of specific script communities within central Greece (see Jeffery 1990).

From an experiential perspective, the Greek alphabet also created a closer link between speech, song, and writing than had ever existed before; this likely influenced the rapidity of its spread in a predominantly oral culture. Yet literacy, as well as the awareness of and access to this new semiotic system, did not happen instantly. Writing must also be understood in the context of contemporary and previous symbolic vocabularies, beginning in the Prehistoric Iron Age. As signs on clay, the most significant of these are potters' marks.

Potters' marks are painted, impressed, stamped, or incised marks put on the surface of a pot before firing, and are attributed to the potter him- or herself (Papadopoulos 1994, 439; 2017b). Signs painted or incised after firing are typically not considered potters' marks, because their makers could have been anyone. Yet, as visual and symbolic referents, such marks may do similar things. The most common interpretation is that these were makers' marks, or that they were intended to play some role in production or distribution, or both (Papadopoulos 1994, 473). Cross-culturally, potters' marks are simple identity tokens, though on a very basic level they correspond to a person or entity; ultimately, the system of communication is quite limited, there being only a relatively small group of individuals to which they are relevant (Houston 2004, 227). Most importantly, they are nonlinguistic. So, while the medium of expression is the same as that of the earliest (known) Greek writing-pottery-these notational systems (potters' marks and writing) are quite distinct. The only possible (though not insignificant) link to writing is that Early Iron Age potters' marks may demonstrate the desire of potters to inscribe meaningful signs on clay.

Powell $(1989,349)$ lists some 20 locations that should be included in the "first generation" of Greek alphabetic writing, the most significant being Pithekoussai, Eretria, Athens, and Kommos. To these can be added Methone and probably other places as well, as new evidence comes to light (map 29). ${ }^{14}$ While Powell's "first generation" includes everything with a plausible date before $650 \mathrm{BCE}$, a more refined chronology is illuminating. The very first generation of certain alphabetic inscriptions comes in the eighth century, which is documented at the sites listed above. Predecessors in the form of single letters or Phoenician script appear slightly before (chiefly in Crete), and other very early inscriptions in Phyrgian are known from Gordion. Greek inscriptions dated to the seventh century are more widespread, including sites in Sicily, Asia Minor, and the Aegean islands. The pattern is clear: sites in or closely linked to central Euboea exhibit the earliest examples of alphabetic script, although writing spread quickly from there (see also Bourogiannis 2020, 158-63). The recent evidence from Eretria, Lefkandi, and Methone (an

14. For more on early inscriptions and data in map 29, see Wade-Gery 1940; Langdon 1976; Jeffery 1980, 1990; Boardman 1990; Sass 1990; Buchner and Ridgway 1993; Palme-Koufa 1996; Csapo, Johnston, and Geagan 2000; Coldstream 2003; Kenzelmann Pfyffer, Theurillat, and Verdan 2005; Theurillat 2007; Besios, Tzifopoulos, and Kotsonas 2012; Clay, Malkin, and Tzifopoulos 2017. 

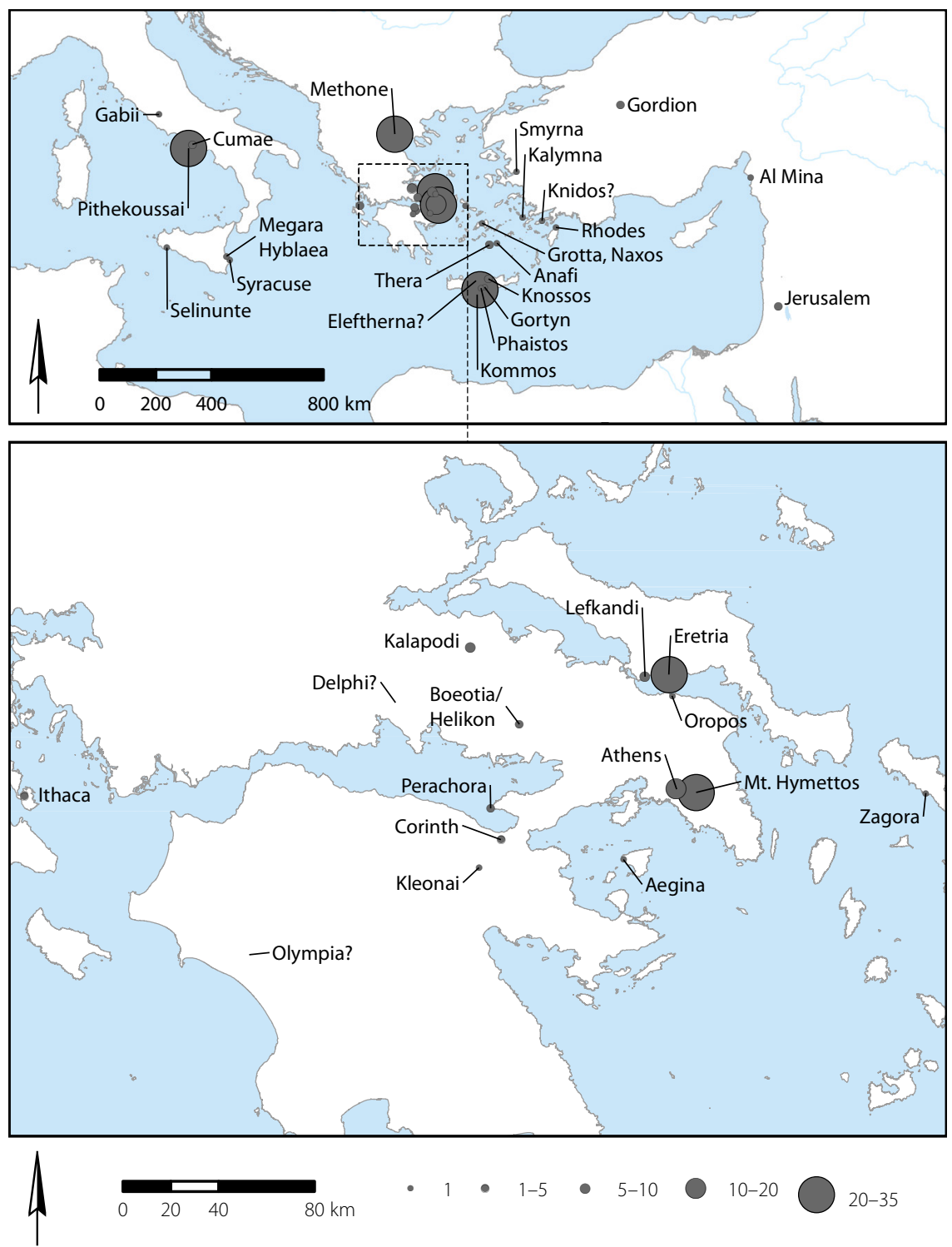

MAP 29. Early Greek inscriptions in the Mediterranean, showing location and quantity.

Eretrian colony) highlights this trend, adding to already significant quantities of evidence associated with Euboea. A look at the wider Euboean Gulf can also be instructive, as the earliest alphabets in Boeotia, Thessaly, Lokris, and Attica exhibit commonalities as links between these small worlds. The current evidence suggests that ideas may have traveled more quickly and more completely-for example, between Euboea and Pithekoussai-than they did between Euboea and Boeotia, 
or Euboea and East Lokris, since Boeotia and East Lokris adapted, rather than simply adopted, new innovations.

This distribution of the earliest writing overlaps quite clearly with other traces of Euboeans in the Aegean and Mediterranean-namely, in terms of reported colonial activity (compare maps 28 and 29). This has led to several suggested contexts for some kind of adaptive moment. The Euboean connection and the Euboic alphabet indicate that this moment occurred in a location where Euboeans and Phoenicians were in close contact. Indeed, several of the earliest loci of Greek script fit this criterion: Al Mina, Lefkandi, Eretria, Methone, or Pithekoussai, since both Semitic and early Greek writing (at least in the form of graffiti) has been found at these places. The initial stages of innovation could have taken place anywhere in the course of interactions between Euboeans and Phoenicians (Euboea, the Levant, Cyprus, or Italy), but the fact remains that central Euboea appears to be the most significant common denominator or central hub of an early alphabetic network. ${ }^{15}$

The social circumstances are of further interest. Gnanadesikan (2009, 208-14) provides a thought experiment about a Greek learning the alphabet in a Phoenician potter's workshop. She imagines a Greek potter being instructed in the value and potential of the alphabet for recording information. Such a situation is not implausible for the initial phases of the appearance of the alphabet, when we have only a name, a word, or a few letters. Pappa (2019) has recently linked the spread of the alphabet in the Mediterranean to the monetization of Early Iron Age economies and the use of documentation in credit-based transactions. The initial Phoenician expansion described in the previous chapter provides a plausible context for an initial proliferation of Phoenician writing on perishable materials. Indeed, many early Greek inscriptions and other marks seem to indicate ownership (on drinking cups, on the one hand, and storage and transport vessels, on the other) and can be seen in a commercial context.

There is also a significant transition in the use of Greek alphabetic writing to recording phrases, especially hexameters. Objects like the Cup of Nestor from Pithekoussai highlight the true innovation of recording speech, which changed the way material culture could actively participate in social contexts, such as sympotic situations involving communal dining, drinking, and the recitation of poetry (see figure 7a). Węcowski (2017) has argued that this combination of commercial and convivial interests indicate elite trade and symposia as the most frequent contexts for early Greek writing. We should also note that these contexts are

15. Papadopoulos (2016b) notes that Phrygians must be added to this mix too, since the similarity in Greek and Phrygian vowels suggests that they must have been developed together. This observation leads him to suggest Methone, in northern Greece, as the possible location of the invention. Indeed, the north Aegean, in general, and Methone, in particular, do have a significant confluence of Greek, Phoenician, and Phrygian elements. On the other hand, central Euboea has a much greater time depth of contacts with the Phoenicians. 


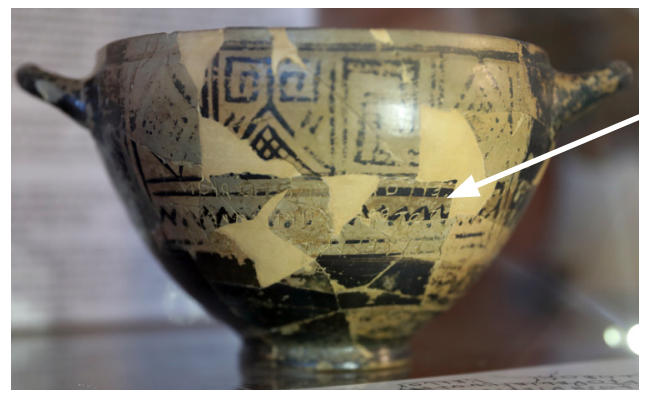

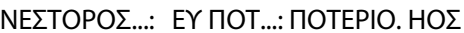
$\triangle$ ATO $\triangle$ EП...: ПОTEPI.(.): HY TIKAKENON

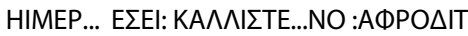
ES

I am the good-drinking cup of Nestor. Whoever drinks from this cup, immediately desire of beautifulcrowned Aphrodite will seize him.

a
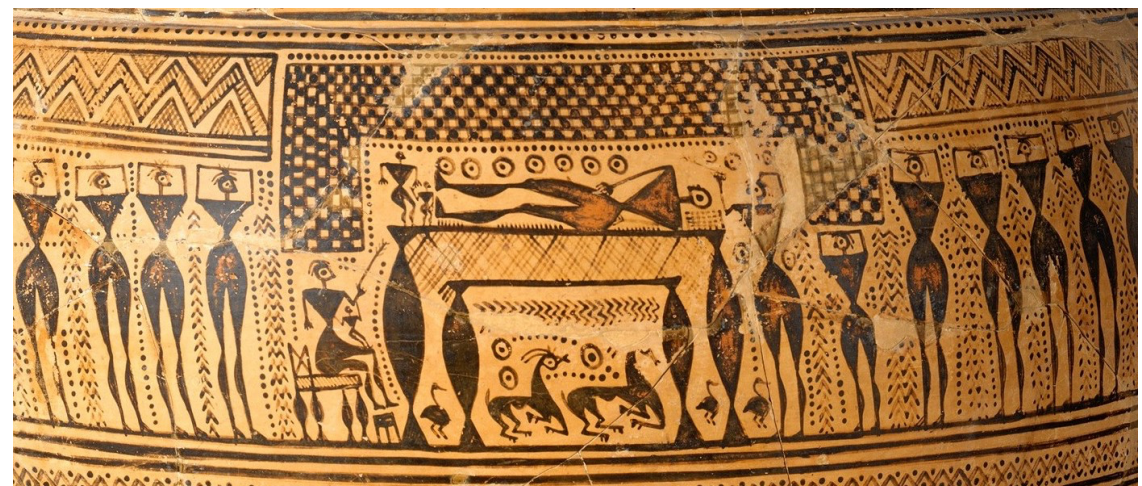

b

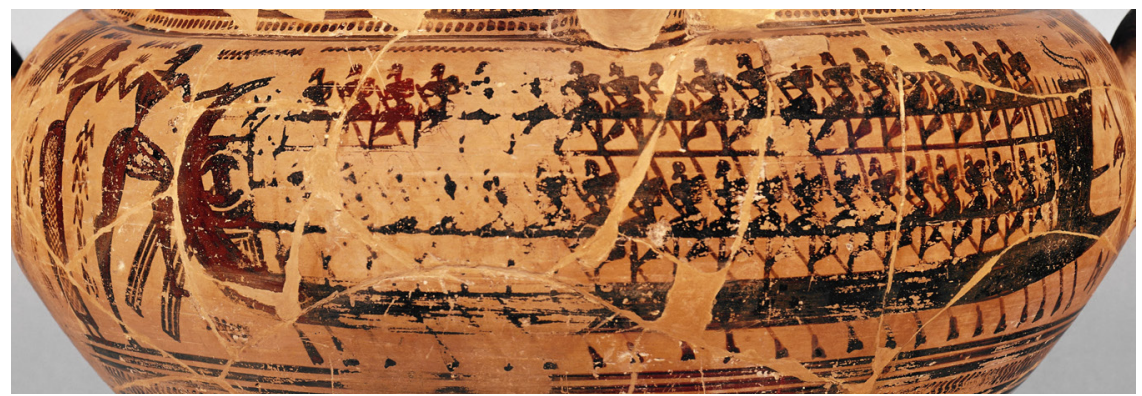

C

FIGURE 7. Examples of Geometric pottery with early writing and figural scenes: "Nestor's cup" from Pithekoussai, with inscription and translation (a: photo by Marcus Cyron, CC BY-SA 4.0); the "Dipylon Krater," showing a funeral scene with mourners (b: photo made publicly available by the Metropolitan Museum of Art, CC O); the "London Abduction Krater" (c: ( ) The Trustees of the British Museum, shared under CC BY-NC-SA 4.o license).

almost exclusively in significant ports of trade, with evidence for both Greeks and non-Greeks (in the first place Phoenicians, but later others as well) operating in the same socioeconomic environments. Most importantly, these situations 
represent a change in what writing does and who uses it-it is no longer a part of state apparatuses; instead, it is used in small-scale, local practices of group formation and exchange in places of convergence between members of different cultural groups.

\section{Figures, Narratives, and Visual Culture}

The iconography of geometric vase painting can be divided into two broad and overlapping categories: scenes of life and scenes of myth (though the latter should be considered the exception rather than the rule). ${ }^{16}$ Both involve narrative and play important roles in the construction of the social world of the observer. These scenes must also be viewed as the products of the social world of the maker. Scholarship on Homeric poetry has long focused on the dialectic between the subject matter of a distant past and the contemporary context of production, which results in the sort of conflative temporality described above. Visual art is more ambiguous, which may partly explain why less attention has been paid to similar such conflations in early Greek art (i.e., of a mythical world and a real world). Nevertheless, part of the reason for the rapid spread of early Greek writing was certainly the specificity of meaning that it carried. We might see a parallel case in the rapid proliferation of figural art in the Late Geometric period. As with writing, we have a few earlier examples in MG and even EG vase painting, especially from Athens (Coldstream [1968] 2008). Whitley (1991, 47-48) notes that there is also a considerable amount of Protogeometric figural material from other sites-namely, Knossos and Lefkandi. And figurines, while rarer in the Prehistoric Iron Age, were always present in the Greek artistic repertoire. The proliferation of images after 750 BCE, however, is coincident with other processes of intensification discussed above, and should therefore be viewed as part of the same broad set of social developments.

I argue that figural scenes of Geometric art prioritize contemporary life over myth, and that they are focused especially on circumstances with which their observers were likely to have been familiar. Morris $(1987,194)$ suggests that interest in an age of heroes was the likely cause for the resurgence of figural art in the mid-eighth century. This is in partial agreement with Snodgrass's (1980a, 65-78) view that the heroic and contemporary both play a role in Geometric figural art.

16. The classic studies of Geometric pottery are by Coldstream ([1977] 2003; [1968] 2008). Iconographic discussion has long dominated attempts to identify relationships between images in early Greek art and Homer and myth, as scholars have sought to find particular Homeric or mythological episodes in art that are presumably contemporary with the earliest literature (see, e.g., Carter 1972; Ahlberg-Cornell 1992). Thematic studies, including the relationship of art to citizenship, the Near East, Homer, and cult, can be found in Langdon (1997). Snodgrass (1998) provides a counter to earlier, Homer-focused scholarship; he lends Geometric artists more agency in creating particular episodes without needing to strictly adhere to, or even have knowledge of, Homer. Most recently, Langdon (2008) has shown how more commonplace topics of childhood, maturation, gender, and ritual feature in Geometric art; her particular emphasis is on rites of passage. 
I would go beyond this to suggest that even scenes that can be interpreted as mythological are meaningful for their relationship to experiences familiar from the real world. This is similar to Langdon's (2008) view that narrative scenes in the Geometric period were meant to illustrate rites of passage, social inequality, and gender relationships. While a concern with the heroic world had long been present, its coincident expression in art and literature suggest that these things were part of a common interest in materiality.

Among the many narrative scenes, there is a preponderance of certain types. Funerals, battles, dances, and processions abound, and images associated with travel, both maritime and terrestrial, also stand out. Well-known examples, such as the massive Dipylon funerary krater and amphora, are self-referential rather than mythological in focus, in that they depict the type of event they are meant to commemorate (see figure $7 \mathrm{~b}$ ). It is doubtful that battle scenes referred only to epic and not to some violent realities to which the proliferation of weapons found in male burials would attest. Ritual scenes, such as collective dances, record groupformation practices well known in the later Greek world and for early agricultural communities in general (Garfinkel 2003, 85-97; Langdon 2008, 158). Such dances may have been part of the same sympotic events to which early inscriptions on drinking vessels refer (see figure $7 \mathrm{a}$ ).

Numerous scenes involve travel by land or sea, with many of them placing a special emphasis on horses or chariots, on the one hand, and ships, on the other (Kirk 1949; Greenhalgh 1973; Crouwel 1992). The London Louterion shows a man leading a woman onto a ship with many rowers on one side, and a group of two chariots and a rider on the other (see figure 7c; Langdon 2008, 19-21). This composition has been interpreted variously as a depiction of a funerary scene culminating in a ship race; a specific mythological scene, such as the abduction of Helen (by Paris, or her return with Menelaos) or Ariadne or Medea; and a more general scene of abduction as a metaphor for marriage (Langdon 2008, 32). Taking a step back from these specific interpretations to look at the contextual details can also be instructive. At its most basic level, the pot shows a preoccupation with locomotion, regardless of the presence of reference, allusion, or metaphor. Movementboth by land and sea, and in chariots and ships respectively_is consistently linked to marriage, one of the types of necessary interactions presented in the nearestneighbor model of intercommunity relations described above.

The specific and general themes of Greek Geometric imagery were created as an expression of collective, cultural identity in the face of a rapidly expanding world. That is, as people came into increasing contact with "others," an interest in expressing aspects of one's own cultural practices grew. This involved religious beliefs and funerary customs; depictions of especially significant events, such as the dangers of sea travel and battle; and aspects of elite life, such as hunting or horse taming. At the same time as this symbolic vocabulary was being established both in central Greece and elsewhere, regional styles became increasingly divergent, 
as craftspeople and regional cultures evolved material expressions in a world of increasingly apparent difference (Coldstream 1983). The role of images in identity formation thus worked on multiple levels, from the trans-Mediterranean to the local. Local identities were expressed through the depiction of particular regional styles and cultural practices, though these were often common across a wider region. Such a mode of expression served to reinforce what it meant to be "us" in a world increasingly encountering "them." Moreover, images served to communicate such messages over long distances and in ways that did not depend on a shared spoken or written language.

\section{Creative Dialogues between Writing and Painting}

At the core of the media revolution in the eighth century is the increased capacity to transfer words, symbols, images, and meaning through space and time. Visual culture and the written word are rarely treated together, despite the fact that to write and to paint are the same word in ancient Greek: $\gamma \rho \alpha \operatorname{\varphi s} \iota v$ (Papadopoulos $2017 \mathrm{~b}, 38$ ). There is a long tradition of ascribing Homeric inspiration to various works of Geometric art, though this tradition obscures and precludes the creative and expressive capacity of artists, poets, and craftspeople other than Homer (Snodgrass 1998; Langdon 2008). Expressions of myth in writing and painting were part of the same phenomenon, rather than one following from the other. Discrepancies between depictions reflect a plurality of versions and a world in which inscription was a creative act, and not simply a means of recording. Writing and painting were therefore aesthetic and material practices, in which words and images on things became active participants in social life (see also Pappas 2011, 2017).

An archaeological perspective shows how writing and imagery developed together in the Protohistoric Iron Age as part of communal activities comprised of eating, drinking, poetry recitations, and competitive display. While such practices have a long history and, as we have seen, are rooted in feasting practices going back at least to the Mycenaean period, new and distinct material engagements appear in the Protohistoric Iron Age. At the same time, local practices took inspiration from stories brought from far-off locations, cross-cultural encounters, hazardous journeys, and encounters with other people, cultural practices, and expressions.

The subject matter of early poetry and images is also multiscalar, ranging from epic, long-distance journeys to the exigencies of daily life. Just as Homer and Hesiod stretch from the heroic to the mundane, early painting includes varied themes from shipwrecks to horse taming to marriages and funerals. The implications of the active practices and underlying structures evident in this media revolution are many, and they relate to aspects of Greek life-from politics to poetry. While the discussion in this section has been of the "Greek world" writ large, central Greece played a particularly significant role during this stage. With Boeotia as the homeland of Hesiod, the earliest personality in Greek literature, and with Euboea 
as a possible homeland of Homer, there is a significant literary presence. ${ }^{17}$ Moreover, the Euboean and especially the Attic styles of painting, especially figural painting, continued to be influential in other spheres. Finally, central Euboea in particular was a demonstrably significant hub in both early colonization movements and the rapid dispersal of the Greek alphabet. This confluence of development in central Greece is not coincidental but is rather the result of accumulative growth on a regional scale. Ultimately, however, written and visual culture reflect a world that is both more local and more "global" than anything we have seen up to this point in the Mediterranean.

\section{THE MEDITERRANEAN CORRUPTED}

"Progress is movement toward movement, movement toward increased movement, movement toward an increased mobility" (Sloterdijk 2006, 37). While Sloterdijk presents a formula for modernizing processes, this also applies to the revolutionary self-intensification seen across the Mediterranean in the eighth century BCE.

The Protohistoric Iron Age saw the intensification, through permanent settlement and habitual use, of the first truly Mediterranean-scale networks across the "corrupting sea" of Horden and Purcell (2000). This was anticipated in the Prehistoric Iron Age with the beginnings of the Phoenician expansion (see map 23, pp. 181-84). By using the term "intensification" in this case, I point to two things: first, the sheer number of new settlements established from distant points of origin; second, their permanence and the regular flows of people, materials, and information that followed.

\section{Imports, Exports, and Depositional Patterns}

There is a significant shift in spatial patterns of material consumption in the eighth century, patterns that represent an expansion of Greek activities throughout the Mediterranean. This is reflected both in the record of imports for foreign materials and products to Greece and in the dispersal of elements of Greek material culture (chiefly painted pottery) to other parts of the Mediterranean-from Iberia to the Levant (for the most recent summary, see Murray 2017, 103-12, 203-8).

There are more imports in Greece during the Protohistoric Iron Age than in any other period studied in this book (map 30). Murray $(2017,113)$ records some 543 objects from Geometric contexts in Greece, as opposed to 152 Protogeometric, 136 LH IIIC, and 228 LH IIIB objects. ${ }^{18}$ The change in distribution and depositional

17. Hesiod identifies himself as a man from Askra (Works and Days 640). The identity of Homer is widely debated, including whether "Homer" even represents an individual. With no reliable biographical information for such a semilegendary figure, several homelands have been posited. These include Chios, Ionia, and Euboea (Powell 1991; Morris and Powell 1997; Lane Fox 2008).

18. It should be noted that Murray's $(2013,2017)$ use of standard pottery chronologies for the division of periods is different from the periodization used in this book. The result in this study is 

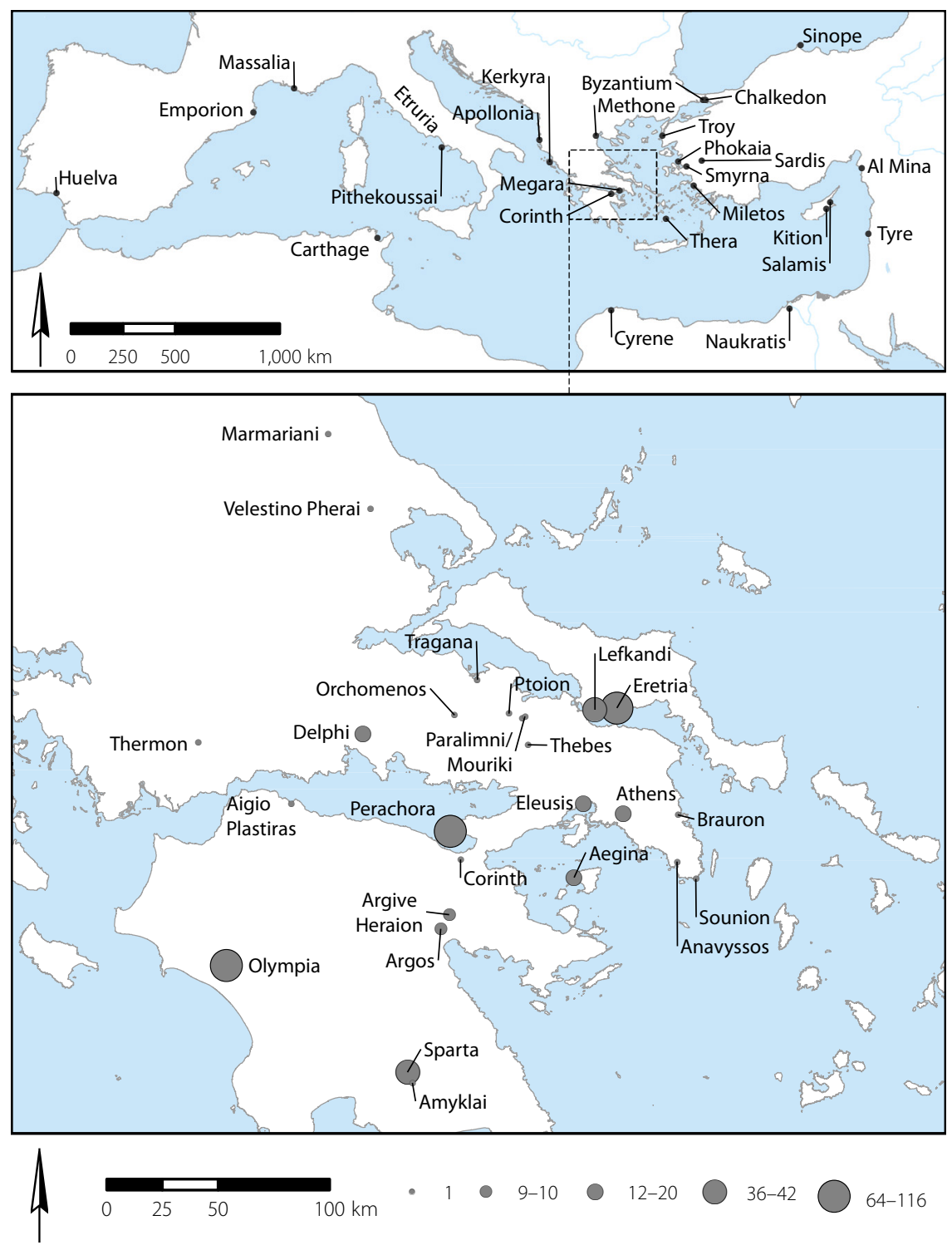

MAP 30. Sites mentioned in the text with evidence for long-distance interaction, especially colonies and mother cities (top) and Geometric period imports to Greece (bottom) (import data from Kourou 2015; Murray 2017, 102-11, table 2.6).

some evening between the Prehistoric Iron Age and the Protohistoric Iron Age, but since most of the Geometric imports described by Murray are either Middle or Late Geometric, the general pattern still holds. The biggest difference is that Murray would count many Subprotogeometric finds from 
patterns is also significant. Imports dated to the Protogeometric period show a clear spatial distribution along and around the Euboean Gulf, with a handful of examples coming from other locations (see map 23). This distribution reflects a pattern of long-distance interactions that began to intensify in this zone in the Postpalatial Bronze Age, and then became even more acute in the Prehistoric Iron Age. In the Geometric period, however, and really from the Middle Geometric (eighth century) onward, we see an influx of imported products across the Greek landscape. Most notably, there is a sudden infilling in the Peloponnese, which had been nearly empty of imports in Protogeometric times (compare maps 23 and 30; see also Kourou 2015; Murray 2017, 102-3).

The majority of these imports were deposited in sanctuaries, reflecting their growing significance as venues for interpolity competition and display, as discussed above. This stands in contrast to the tomb/individual-based consumption of imports noted in the Postpalatial Bronze Age and Prehistoric Iron Age. There are two possible reasons for this sudden influx of imported objects into sanctuaries. On the one hand, their exotic nature makes them valuable symbols of wealth, connectivity, and prestige for the individual or group dedicating them in this highly visible setting. On the other hand, this may already signal foreign interests (well known in later times) in particular Greek sanctuaries-most notably the ones that would become Panhellenic shrines later on.

Even as more foreign goods were coming into Greece than ever before, more were going out - at least in terms of the Greek pottery that has been documented in foreign contexts (Saltz 1978; Coldstream 2003; Fletcher 2008). The most significant concentrations of these materials are in the Levant, Cyprus, and western Italy, though finds in smaller quantities have at this point been discovered as far away as at Huelva, in Spain (Gonzáles de Canales, Serrano, and Llompart 2006). Most of the Italian finds from the beginning of the eighth century are Euboean, and they are limited in distribution to places that are associated with Euboean colonies. By the end of the eighth century, Corinthian wares could be found throughout much of the Italian peninsula. While a wide variety of contexts are present, many drinking and dining sets from elite tombs in Italy, Cyprus, and the Levant suggest that the people in these areas were especially interested in high-quality Greek pottery, particularly in contexts that were related to the convivial occasions so important for social display and cross-cultural interaction. For example, at the elite cemeteries of Salamis, on Cyprus, a wide range of Greek practices and materials is present; these probably represent a conflation and hybridizing of Greek and Cypriot traditions from the Bronze and Early Iron Age (Blackwell 2010). A wider range of pottery shapes is present in Anatolia and Italy than in Cyprus and the Levant, which is probably related to the foundation of permanent settlements in these locations.

the Toumba cemetery of Lefkandi as Geometric (since they are contemporary with Attic Geometric), while I include them in the Prehistoric Iron Age. 


\section{From Colonial Stories to Mediterranean Histories}

Lane Fox (2008), drawing primarily on the evidence of myth, has highlighted "travelling heroes" from Euboea as key agents in the eighth-century Mediterranean. Later textual references to Greek settlements overseas also provide glimpses of early Greece in its Mediterranean context, although all these sources are written from temporally and culturally specific perspectives that result in a somewhat distorted view. While the case of Euboean apoikiai was discussed above, we must note that this was part of a larger set of movements involving both Greeks and their less textually visible counterparts throughout the Mediterranean. ${ }^{19}$ The timing and distribution of these apoikiai is significant, not only for our understating of the period but also for our understanding of regionalism as variable and multiscalar. There are three elements that are relevant here:

1. Colonization movements as coherent entities are largely text-based phenomena-tied up in many of the same identity politics that plague notions of the Ionian or Dorian migrations (see, e.g., Malkin 1998; Hall 2008; Mac Sweeney 2017; see also chapter 5, pp. 187-89).

2. As we have seen in previous chapters, the intensification of Greek activities overseas in the eighth century is both part of a long tradition going back to the Mycenaean period and part of wider, multicultural processes in the Mediterranean (Papadopoulos 2001, 2014).

3. The reification of Greek colonization in modern scholarship has served to simplify a complex set of social phenomena in ways that have obscured both the variety of apoikiai and the significance of non-Greek actors (and indeed notions of "Greekness" as well) (Hurst and Owen 2005; Hodos 2006, 2020).

The main factor that makes the eighth century different in terms of Greek activities overseas is that during this period an intensification of activity resulted in permanent settlements that are preserved in the archaeological record, mentioned in historical sources, and last a significant amount of time. The timing and distribution of these settlements is significant. While the eighth century certainly saw revolutionary developments on this front, the bulk of Greek settlements outside of the Aegean were not founded until the seventh and sixth centuries.

Several explanations have been put forward concerning the timing of widespread colonization movements (Descoeudres 2008, 293-96). The two most common are (1) population growth and pressure on agricultural resources in the face of expanding settlement and (2) the quest for metals. Both fit well enough with

19. The bibliography on Greek colonization is vast. For overviews, see Boardman 1980; Ridgway 1992; Tsetskhladze 2006, 2008. The term "colonization" is still commonly used to describe these movements, even though it has long been argued that this is an unsatisfactory and misleading term (Purcell 1990, 56; Osborne 1998). Much recent work has rightly focused on the non-Greek contexts and counterparts of Greek apoikiai (e.g., van Dommelen 1998, 2005; Hurst and Owen 2005; Hodos 2006, 2009, 2020; Pappa 2013; Donnellan, Nizzo, and Burgers 2016; Lucas, Murray, and Owen 2019). 
the combined evidence of diachronic settlement patterns and Greek activities in Italy going back to the Mycenaean period, but neither explanation is very satisfying by itself. Not all regions founded colonies or seemed to respond to settlement growth in the same way. We must therefore look to historical, contingent explanations for settlement expansion, as discussed above in the case of Chalkis and Eretria. Whether the specific interpretation of a relationship with the Lelantine War is correct, the practice of establishing apoikia, first in Italy and then elsewhere, does seem to have originated in Euboea, with other areas following suit quickly after. The rapidity of this development-as with others in the eighth century-must be linked to increased local and regional interconnectivity across mainland Greece as well as to other developments in intercommunity engagement (with regional sanctuaries) and media (writing and figural art). The overall pattern of regional variation in both timing and intensity of sending out colonies signals that different regions or polities were pursuing different routes toward their interactions abroad but also learning quickly from one another. Interaction at sanctuaries and competitive emulation must have played a major part in this phenomenon, along with fissioning groups within particular communities, from which individuals and families struck out to seek greater political fortunes in new landscapes.

The geography of the earliest apoikiai in the eighth century also sheds light on initial strategies on the part of Euboeans, which were probably learned from Phoenicians and then applied in other contexts. The initial positioning of new Greek settlements just outside areas of Etruscan influence and, in the Phoenician case, at places like Carthage is highly strategic and worth considering in light of other comparative contexts (see Gailledrat, Dietler, and Plana-Mallard 2018). Somewhat neutral locations, outside the interested parties' main spheres of influence, and with easy access to the sea or other corridors for movement, are typical of emporia and other places of initial settlement. These characteristics are highlighted in the location of Pithekoussai, just outside the bay of Naples, which would remain a long-term nexus of maritime activity. Methone, too, at the mouth of the Haliakmon River, offers the opportunity for inland navigation and lateral movement across the northern Aegean.

\section{Cultures in Contact Across the Middle Sea}

Toward the end of the eighth century, the city-states of Phoenicia, with the exception of Tyre, were overrun by the expanding Assyrian Empire, and even Tyre was forced to pay excessive tribute (Aubet 2001, 54-58). Part of this expansion may be attributed to the power vacuum in the Levant left by Egypt, which became increasingly fragmented during the Third Intermediate period (1069-664 BCE) and in the mid-eighth century was facing a Kushite incursion from the south (Bard 2008, 267). The tribute demands on Tyre magnified interest abroad in the metalliferous regions of the central and western Mediterranean, with which it had already established connections. 
In Cyprus, both Phoenicians and Greeks maintained major interests and contacts, ethnically Greek and Levantine people having lived on the island since the Bronze Age (Iacovou 2005). The hybridity of the eighth century was by this point the result of a long, ongoing process, and the inhabitants of the island itself should be viewed as distinctively Cypriot, though with traceable Greek and Levantine backgrounds. Kition is typically seen as a Phoenician colony by this time, while the royal tombs at Salamis are suggestive of common ties to Greece, as noted above (Smith 2009, 6-13; Blackwell 2010). This mix of cultural elements and connections is hardly a surprise, since Cyprus lies geographically between the Phoenician Levant and Geometric Greek world of the eastern Aegean and western Anatolia.

By the time Greek and Phoenician settlers arrived in the central Mediterranean, Etruscans were already involved in a thriving central Mediterranean network that included Sardinia, trans-Alpine and trans-Apennine Europe, and the Baltic, as well as the entirety of the Italian peninsula and the Adriatic (Haynes 2005). This network had already been tapped by Phoenicians and (probably) some Greeks in the Prehistoric Iron Age and was tied together permanently in the eighth century. In Sicily, the reaction to new arrivals was quite different, as the centralized, hierarchical settlements of the Late Bronze Age and Early Iron Age seemed to retreat inland and become less socially stratified (Hodos 2006, 92).

North Africa saw the founding of Carthage under the agency of Tyre, which itself became a powerful colonizing force in the central and western Mediterranean, although the height of this activity did not occur until after the eighth century. The key point here is the position of Carthage as it relates to a wider central Mediterranean network, rather than a particular set of resources.

The foundation of permanent settlements created hubs that keyed into, but were outside of, the most active indigenous interaction zones. Thus Greek and Phoenician settlement overseas was by no means an attempt to cover or "colonize" the Mediterranean. While my focus here has largely been on Greeks and Phoenicians, there is still a need for a better understanding of local processes and responses to these Mediterranean expansions, as well as interactions between these two groups (see, most recently, Hodos 2020). Central Euboea, Pithekoussai, Methone, Al Mina, and Kition provide examples of such interactions. For the first time, these places created habitual engagements-material, personal, and conceptual-across the Mediterranean. And, from these locations, notions and material expressions of "others" were introduced into their own local and regional networks.

The multicultural settlement at Pithekoussai represents both a beginning and an end. Located almost in the exact center of the Mediterranean, it represents the lynchpin by which the entire basin for the first time becomes integrated through permanent settlements. By the time Euboeans settled here, Phoenicians had already established a presence in the bay of Cadiz, on the other side of the strait of Gibraltar (the Pillars of Herakles). The Phoenician, Greek, and Italic populations that lived together at Pithekoussai were thus connected by only a few links to all 
shores of the Mediterranean, were involved in established maritime networks on all sides, and shared new sets of social and economic material practices at a local level (Donnellan 2016). But certain separations also started to happen at this time as well. After Pithekoussai there do not seem to be any more "joint" settlements, and the colonial histories of Phoenicians and Greeks take decidedly different paths. In the central and western Mediterranean there is a fairly clear divide between the northeast for Greek and Etruscan activity and southwest for Phoenicians. This is not to say that interaction did not occur-it certainly did, and it is clear enough in both imports and exports, as well as in shared elements of "elite" material culture (Stampolidis and Giannopoulou 2012). In some ways, these interactions seem to have been more culturally significant during earlier periods, even though evidence for them is much more abundant from the "orientalizing" period of the seventh and sixth centuries BCE. Perhaps the divergence between Greek and Phoenician interests is simply a matter of who established lasting presences in these places first and how such presences were received by local communities. The Phoenician route, for example, was to go directly to the rich metal sources of southeast Spain and the Guadalquivir river valley, stopping at important points, including the metal-rich island of Sardinia, along the way. Pithekoussai was an outpost to access the metal-rich landscapes of Etruria, but it was perhaps eventually seen as too far out of the way of already established interests farther west. Maintaining networks requires considerable effort and cannot be sustained on all fronts at once. It should not be surprising, then, that different groups sought different interfaces after an initial period of growing together.

This geographical divergence is also manifest in aspects of material culture in the long term. While a sort of elite, international style did develop during this period, the media of decorated pottery are where we see the greatest divergence between the places of Greek and Phoenician interface. Etruria and southern Italy very quickly became consumers of Greek material and visual culture, though both developed their own distinct forms. Such blending seems to happen less in Phoenician colonies, but this impression is at least partly attributable to huge gaps in our knowledge concerning North Africa and considerable disciplinary separation between Iberian and other Mediterranean archaeologies. A final point of divergence is that concern with the sea and seafaring is not always directly manifest in aspects of Phoenician visual culture. This does not, of course, mean that it was not present in the visual experience and popular imagination, since it certainly was in places like Pithekoussai. One of the more noteworthy things to come out of this comparison is the rather stark difference between a Greek interest in seafaring in popular media and an apparent lack of such an interest in the Phoenician case (at least in terms of what is visible to us today).

Network distances shrank in the eighth century BCE. With the addition of just a few permanent (or at least habitual) links between central Greece and the central Mediterranean, it became possible to reach nearly any point in the Greek world 
from most places in the Mediterranean, passing through increasingly multicultural hubs. At any given time, then, individuals living in central Greece were just a few links away from inhabitants (both native and immigrant) in Italy or the northern Aegean. Moreover, through multiethnic places like Pithekoussai or Al Mina, they were only another link or two from Sardinia, Iberia, North Africa, the Levant, and the wider Phoenician world. It is not the novelty of making such connections that was significant but their intensification through the establishment of permanent communities, which were deliberately engaged in the more widely connected webs of their new locations.

\section{CODA: FROM VILLAGES TO POLEIS}

In concluding this chapter, I look to the Archaic period, pointing in particular toward the scalar differences that characterize it, and contrasting it with the periods to which the bulk of this book has been devoted. It is only in the seventh century (rather late, in fact, and continuing into the sixth) that the transitional period of early Greece concludes, arriving firmly in the Archaic Greek world.

Processes begun in the eighth century do not really become widespread until the seventh and sixth centuries, when we see a transition from a world of complex village communities to the world of Archaic and Classical Greek city-states. That this happened rather suddenly should come as no surprise, given the speed with which state formation tends to happen. The Aegean alone has several instructive examples, including the rapid development of Mycenaean palatial systems discussed in chapter 3 and models of revolution over evolution for Minoan Crete (Cherry 1983a; 2010, 138; Manning 2018). This is not to say that gradual changes do not happen, but rather that major changes tend to happen quickly, as punctuated equilibria that affect multiple subsets of society at once. Renfrew (1972, 36-44) described this as the "multiplier effect" in characterizing the Bronze Age emergence of civilization in the Aegean. This idea was revisited by Snodgrass (1980a, 54) in the case of eighthcentury Greece, though the final result seems most applicable to the seventh.

The seventh century BCE-the early Archaic period-has long been problematic for archaeologists and historians. Étienne (2017, 9), for example, begins a recent summary with the heading: "Did the seventh century exist?" This is a reference to the difficulty in distinguishing this century materially and textually from the eighth, on one side of the chronological spectrum, and from the sixth, on the other. Athens and Attica have received by far the most attention in terms of both the archaeological and literary record. Studies of burial, settlement, and pottery decoration are neatly summarized by Osborne (1989), who highlights that these aspects of the material record are largely ignored by historians, up until history "begins" with the Kylonian affair of about 630 BCE (a coup which the recently discovered mass grave at Phaleron may-or may not-illuminate [Ingvarsson and Bäckström 2019]). There are also several problems in the archaeological record of the seventh century. The most fundamental of these concerns pottery chronologies 
and the fact that they most certainly overlap, with the Geometric period likely extending well into the seventh century, even as Orientalizing-period styles were developing simultaneously. A welcome influx of recent scholarship has focused on the seventh century specifically. This scholarship has begun to illuminate parts of Greece outside of Athens, and it has brought this crucial, if confusing, time period into sharper focus (Étienne 2010; Brisart 2011; Charalambidou and Morgan 2017; Lemos and Tsingarida 2019; Whitley 2020).

If the eighth century contains the revolutionary spark of the early Greek world, the seventh is where it truly kindled. While the eighth-century settlement pattern represents significant expansion, most of this dates to after $750 \mathrm{BCE}$, and even at that point the evidence is thin in comparison to the seventh and sixth centuries (Foxhall 2013, 215). The developments begun in the eighth century in terms of settlements overseas, polity formation, and early Greek script come fully to fruition in the seventh century, representing the most significant phase transition since the formation of Mycenaean palaces (van der Vliet 2011; Haggis 2013; Small 2019). What is different, however, is that the transition into the world of poleis was both more widespread and more lasting than the regionally specific false starts of the Mycenaean palaces. While problematic ceramic chronologies and settlement studies still have some catching up to do, this scalar difference is borne out through (1) the material signatures of settlement overseas, (2) the growth of central places (major settlements and sanctuaries), (3) the proliferation writing, and (4) the introduction of coinage.

The first wave of colonization movements discussed above seems largely to have been led by Euboeans. By the end of the eighth century, several other citystates were involved, and by the end of the seventh century, communities across the Greek world were establishing apoikiai. A recent count puts the number of apoikiai established in the eighth century at about 30 and the number established in in the seventh at about 60 (see Osborne 2009, 110-21, table 5). Geographical diversification occurred in the location of new settlements as well, as settlements were established in the Black Sea, North Africa, and the western Mediterranean (modern France and Spain), beginning in the seventh century and continuing into the sixth. Indeed, some of the most important and long-lasting examples of Greek settlements abroad were established during this era, reflecting also a much wider range of mother cities: Byzantium and Chalkedon (Megara is the mother city), Sinope (Miletos), Cyrene (Thera), Apollonia (Corinth and Kerkyra), Massalia (Phokaia), Emporion (Massalia and Phokaia) (see map 30, top). Naukratis in Egypt seems to have evolved more organically, since it was established in the seventh century in the location of a long-standing trading emporium. The expanding geography of new communities and the diversity of Greek polities establishing them signal a scalar shift in the organization and activities of early Greek societies, as well as the institutionalization of practices that began in the eighth century.

As for the political structures of communities themselves, these seem to have undergone their most fundamental transformations in the seventh, rather than 
the eighth, century, although we must rely mostly on historical sources for understanding these. Whitley (2020) points out that the polis was largely unknown to Hesiod, writing around $700 \mathrm{BCE}$. He is aware of larger communities than his own village at Askra (in Boeotia) but he says nothing of the monumental architecture and complex social organization that characterize later Greek poleis and other states. By 600 BCE, we can see civil strife between aristocratic factions at Athens, complex administrative offices concerning temples and ships, and political communities with codified systems of written laws on Crete. Whitley $(2020,170)$ further notes the extraordinary rapidity of these processes of emergence, which took place between about 700 and 640 . Like colonization, the spread of such institutional practices only could have undergone such intensifying processes in the network architecture first established in the eighth century.

The Archaic period was equally transformative for the physical vestiges of increasing social complexity-most importantly in the architectural forms that would come to characterize the Greek city-state. Most noticeable are the systems of fortifications, which became widespread in the seventh century, and by the sixth century were a staple of any polis (Frederiksen 2011). Reflecting on seventhcentury settlements in general, Frederiksen $(2017,192)$ notes: "We could not imagine such communities without neighbourhoods of private houses separated by lanes and streets, without at least one (urban) sanctuary, designated cemeteries, a harbour or landing place, a political and commercial meeting place/agora, and so on" (see also Osborne 2009; Mazarakis Ainian 2017). We could not say this about the much more varied and village-like communities of the eighth century or of any period that came before. Still further material correlates for state formation are visible in the increasing dedications at regional sanctuaries, as well as in the "hoplite revolution" that spread across much of the Greek world in the seventh century (Snodgrass [1967] 1999, 48-60; Foxhall 2013).

Writing was the major catalyst for lasting social organization, the formation of political institutions, and the beginning of proper history. Our knowledge of Archaic Greek political institutions is entirely dependent on the technology of writing, as was their own longevity. As with settlements overseas, there was a scalar difference in the proliferation of writing in the seventh versus the eighth centuries. There are about 20 sites with roughly 160 examples of early Greek writing in possible or definite eighth-century contexts, with most of the examples coming from Eretria, Methone, Pithekoussai, and Kommos (see map 29). For the seventh century, the number of sites and examples more than doubles (Jeffery 1990). While the adoption of the alphabet in the eighth century constituted a media revolution in and of itself, writing did not become part of a truly structural revolution until its seventh-century deployment in political contexts. The eighth century was still very much in the realm of protohistory and mythohistory. The few examples of writing we do have indicate that writing had little to do with the recording of events or societal regulations but was used rather for economic purposes or in 
the convivial contexts of social interaction. By the seventh century, writing had become explicitly political, as it was turned toward the state apparatus of keeping accounts, recording laws and office holders, historical events, conflicts, and alliances. While state-like modes of social organization may be possible without writing, they are difficult to see in the early Greek world until writing and history become distinctly political.

The final fundamentally transformative development of the seventh century was the invention of coinage. Invented in Lydia (Sardis) at the end of the seventh century, coinage became widespread in the Greek world in the sixth and was a hallmark of Archaic poleis that would transform economic transactions and invoke codified political institutions across the Mediterranean. Just as writing intensified social and political processes, coinage was a structuring commodity of value that had an immeasurable impact on the economic systems of an increasingly interconnected Mediterranean (Papadopoulos 2014, 188-90). While the eighth century may have set the stage for the rapid proliferation of the social, political, economic, and material changes enumerated above, it was only in the seventh that they became widespread, institutionalized, and permanent fixtures of Greek societies.

\section{CONCLUSIONS: MOBILITY, MEDIA, AND THE POLITICAL LANDSCAPE}

The developments of the Protohistoric Iron Age in central Greece had major consequences across the Mediterranean. Some of these were shared throughout the Greek world, but there were nevertheless historical circumstances that make central Greece, and several more specific areas within it, stand out. In many ways, Snodgrass's ([1971] 2000, 416) admonition still rings true-that the changes of the eighth century are difficult to put in logical order, although they certainly make more sense when viewed in terms of what came before and after.

In the first place, dramatic growth in the overall settlement pattern suggests a population increase across the Greek mainland. This pattern, however, varies widely across regions. The areas that experience the most dramatic growth-Attica and Boeotia-had also experienced the most significant decline after the collapse of the palaces (although this occurred in Attica much more gradually, and in a very different way). Growth in other regions was marginal, while Thessaly even experienced substantial decline. To me this suggests that we cannot look to things like general population pressure as a singular motivation for the founding of Greek colonies overseas-not least because the regions that would have been most affected by rising populations were not involved in the earliest establishments of apoikiai. We need to look rather to a combination of regionally specific societal trajectories and particular historical circumstances. The latter are rarely detectable in the archaeological record, but in the case of central Euboea there seems to be a confluence of landscape, archaeological, and mythohistorical evidence that 
suggests one way in which such dynamics play out across local landscapes and the Mediterranean writ large.

At the same time, we see developments in the religious landscape that reshaped the way communities interacted with one another, due in part to regional crowding and the encroachment of certain communities into the territories of others. The emergence of regional and interregional sanctuaries as hubs of mediation suggests the evolution of particular types of responses to interpolity competition. More local responses, on the order of individual landscapes and between communities, were manifest in the form of tomb cult.

Framing all of these local and regional developments is a series of long-distance interactions that led to the reappearance of writing in the early Greek world, after a hiatus of around four centuries. This happened within a set of central EuboeanPhoenician interfaces that had been in place since the Prehistoric Iron Age. These same long-term processes provided structures for the establishment of permanent settlements in Italy and the North Aegean. At the same time, the widespread regional connections of Attic and Euboean pottery networks were the avenues through which writing dispersed so quickly after its development. While this does not "solve" the question of the location and timing of the alphabet, it pulls together a variety of circumstantial evidence concerning the structure of multiscalar, multicultural interaction to suggest a plausible model rooted in central Euboea.

This chapter has examined landscape and interaction to provide explanations for historical and cultural processes on the very cusp of history. We know more or less what happened from a variety of historical and archaeological evidence, but this is not enough to explain why or how such developments took place. Network and connectivity models rooted in geographic realities and explicitly multiscalar perspectives can be used to fill these gaps in our knowledge. Moreover, a diachronic approach shows how concurrent historical processes relate to one another and intensify human interactions in ways we might not otherwise have understood. The intensification that happens in the eighth century, especially in the transition from the Middle to the Late Geometric period, shows how social phenomena such as settlement expansion, colonization, intercommunity competition, and technological and artistic innovation acted as mutually intensifying processes across space and time. While these expanded networks and the multiplier effect of simultaneous social change are well known from a descriptive standpoint, it is only by viewing them together that we can arrive at new explanations of social and material engagements. In the case of the Protohistoric Iron Age, the end results are the framework and structures that define the Archaic period, if still in somewhat primitive form. By the end of the seventh century, however, the transition was complete: out of the village societies of early Greece and into the more widely known, more widely recognizable Archaic Greek world. 